\title{
Oral Limonite Supplement Ameliorates Glucose Intolerance in Diabetic and Obese Mice
}

\author{
Akihiro Uchida ${ }^{1, *}$ \\ Taro Yasuma ${ }^{1,2, *}$ \\ Atsuro Takeshita $1,2, *$ \\ Masaaki Toda ${ }^{2}$ \\ Yuko Okano ${ }^{1,2}$ \\ Kota Nishihama' \\ Corina N D'Alessandro- \\ Gabazza $^{2}$ \\ Valeria Fridman D'Alessandro ${ }^{2}$ \\ Chisa Inoue (iD) \\ Takehiro Takagi $^{3}$ \\ Hiroyuki Mukaiyama $\left.{ }^{4}\right)^{4}$ \\ Norio Takagi ${ }^{4}$ \\ Katsumi Shimizu ${ }^{4}$ \\ Yutaka Yano' \\ Esteban C Gabazza (D) ${ }^{2}$ \\ 'Department of Diabetes and \\ Endocrinology, Mie University Faculty and \\ Graduate School of Medicine, Tsu, Mie, \\ Japan; ${ }^{2}$ Department of Immunology, Mie \\ University Faculty and Graduate School \\ of Medicine, Tsu, Mie, Japan; ${ }^{3}$ Iwasaki \\ Hospital, Tsu, Mie, Japan; ${ }^{4}$ Tanisake \\ Corporation, Gifu, Japan
}

*These authors contributed equally to this work

\begin{abstract}
Introduction: Diabetes mellitus is a serious threat to public health worldwide. It causes a substantial economic burden, mental and physical disabilities, poor quality of life, and high mortality. Limonite is formed when iron-rich materials from the underground emerge and oxidized on the ground surface. It is currently used to purify contaminated water, absorption of irritant gases, and improve livestock breeding. Limonite can change the composition of environmental microbial communities. In the present study, we evaluated whether limonite can ameliorate glucose metabolism abnormalities by remodeling the gut microbiome.

Methods: The investigation was performed using mouse models of streptozotocin-induced diabetes mellitus and high-calorie diet-induced metabolic syndrome.

Results: Oral limonite supplement was associated with significant body weight recovery, reduced glycemia with improved insulin secretion, increased number of regulatory $\mathrm{T}$ cells, and abundant beneficial gut microbial populations in mice with diabetes mellitus compared to control. Similarly, mice with obesity fed with limonite supplements had significantly reduced body weight, insulin resistance, steatohepatitis, and systemic inflammatory response with significant gut microbiome remodeling.

Conclusion: This study demonstrates that limonite supplement ameliorates abnormal glucose metabolism in diabetes mellitus and obesity. Gut microbiome remodeling, inhibition of inflammatory cytokines, and the host immune response regulation may explain the limonite's beneficial activity under pathological conditions in vivo.
\end{abstract}

Keywords: insulin resistance, limonite, diabetes, streptozotocin, metabolic syndrome, gut microbiome

\section{Plain Language Summary}

Metabolic syndrome and diabetes mellitus are serious threats to human health worldwide. Supplement of limonite, a natural resource, has been shown to improve stockbreeding and remodel microbial communities. This study shows that oral supplements of limonite improved $\beta$-cell survival and glucose intolerance in diabetic and obese mice, suggesting its potential beneficial effects as a health supplement in these chronic pathological conditions.

\section{Introduction}

Diabetes mellitus is one of the major non-transmissible chronic diseases causing increased disability, significant economic burden, and many deaths worldwide. ${ }^{1,2}$ An international group of specialists reported in 2017 that the economic burden from DM is approximately 1.3 trillion USA\$, which represents $1.8 \%$ of the global gross domestic product. ${ }^{3,4}$ Numerous studies conducted in the United States demonstrated the association of DM with a substantial increase (50-90\%) in the risk of
Correspondence: Esteban C Gabazza Department of Immunology, Mie University School of Medicine, Edobashi 2-174, Tsu-

City, Mie, 514-8507, Japan

Tel +8I 592315037

$\mathrm{Fax}+81592315225$

Email gabazza@doc.medic.mie-u.ac.jp 
several forms of disability, including reduced instrumental or basic activities of daily living and work disability. ${ }^{5}$ The World Health Organization reported that DM was globally the seventh leading cause of death in 2016, with a total number of 1.6 million deaths caused directly by DM. Macrovascular (coronary heart disease, lower extremity arterial disease, stroke) and microvascular (retinopathy, nephropathy, neuropathy) complications are the main responsible for the increased disability, morbidity, and mortality of diabetic patients. ${ }^{5-7}$ In addition, the number of people with DM keeps rising despite efforts by the World Health Organization to reduce its prevalence. ${ }^{8}$ A recent study estimated that DM's global prevalence would increase from 415 million in 2015 to 642 million in 2040 in subjects between the ages of 20 to 79 years old. ${ }^{9,10}$ Therefore, there is an urgent need to develop novel preventive approaches to reduce the prevalence of DM.

Limonite is a natural resource formed by the weathering of iron-bearing materials (eg, hematite, magnetite, and pyrite) that emerge from the underground waters at springs, mine openings, and during the eruption of volcanos. The subsurface waters contain almost no oxygen. Therefore, when the underground waters move to the surface ground, the iron-bearing materials combine with oxygen and precipitate to form limonite. In Japan, limonite can be obtained from Mount Aso, an active volcano located in Kumamoto Prefecture. Limonite is composed of organic (carbohydrate, protein, fat) and inorganic (iron, silica, aluminum, calcium, sulfur, magnesium, potassium, sodium, phosphorus, manganese) compounds, the most abundant component being iron $\left(\mathrm{Fe}_{2} \mathrm{O}_{3}\right) .{ }^{11}$ The ability of limonite to increase the ionic conductivity in lithium-ion of portable electronics, ${ }^{12}$ decrease the radiation permeability of heavy-weight concretes, ${ }^{13}$ enhance coal liquefaction ${ }^{14}$ and stabilize hazardous soil arsenic ${ }^{15}$ has been attributed to its high iron content. However, some properties of limonite are not reproducible using iron alone. For example, during the anaerobic digestion of municipal waste sewage sludge, while the addition of limonite reduces methane formation and lowers the $\mathrm{pH}$, the addition of an equivalent amount of iron increases methane production without affecting the $\mathrm{pH}$ values. ${ }^{11}$ Limonite reduces the release of odorous and irritant gases (hydrogen sulfide, ammonia) from municipal or industrial waste. ${ }^{11,16-18}$ The iron-independent beneficial effects are attributed to limonite's ability to remodel the environmental microbial communities. ${ }^{11,19}$ Indeed, limonite has been associated with enrichment for specific microorganisms. ${ }^{11,20}$ Based on its properties, limonite is currently used as a deodorizer, soil exchanger, or water purifier in some countries, including Japan. Although the mechanism is uncertain, oral limonite supplement has improved performance, productivity, and competitiveness in stockbreeding and fishery.

Previous studies have shown that the gut microbiome plays an important role in the pathogenesis of DM and obesity. ${ }^{21}$ Therefore, in the present study, we hypothesized that an oral supplement of limonite would ameliorate glucose metabolism abnormalities in mice with diabetes mellitus or metabolic syndrome.

\section{Materials and Methods}

\section{Reagents}

The human epithelial colorectal adenocarcinoma cell line Caco-2 was provided by the American Type Culture Collection (ATCC; Manassas, VA, USA). Caco-2 cells were cultured in vitro using Dulbecco's Modified Eagle Medium (DMEM) supplemented with $20 \%(\mathrm{v} / \mathrm{v})$ heat-inactivated fetal bovine serum (FBS) from Bio Whittaker (Walkersville, MD, USA), $0.03 \%(\mathrm{w} / \mathrm{v})$ L-glutamine, $100 \mathrm{IU} / \mathrm{mL}$ penicillin and $100 \mu \mathrm{g} / \mathrm{mL}$ streptomycin (Invitrogen, Carlsbad, CA, USA) in a humidified, $5 \% \mathrm{CO}_{2}$ atmosphere at $37^{\circ} \mathrm{C}$. Baits containing limonite $5 \%$ or $0 \%$ (standard or normal food) were provided from Clea Japan (Shizuoka, Japan).

\section{Preparation of Limonite}

Limonite was prepared and provided by Limonite Japan Co. Ltd. (Kumamoto, Japan). Briefly, the natural limonite produced during the Mount Aso's volcanic eruption (Kumamoto prefecture, Japan) was collected, stored, and then subjected to several processing steps that include weathering, heat drying, pulverization, sieving, and sterilization that take approximately three years. ${ }^{11}$ The processed product was then used to prepare baits containing 5\% limonite. Preliminary studies using baits containing $0.5 \%$ or $5 \%$ limonite showed no adverse events, thus we used $5 \%$ in the experiments.

\section{Experimental Animals}

Male C57Bl/6 wild-type mice (7-9 weeks old) weighing on average $20 \mathrm{~g}$ were purchased from Nihon SLC (Hamamatsu, Japan). The animals were housed in a specific pathogen-free environment in the Experimental Animal Center of Mie University. Mice were bred at a temperature of $21^{\circ} \mathrm{C}$ and under a 12-h light/dark cycle. 
Mice had wood-wool nesting material in their cages (4 mice or less per cage) and had access to water and food ad libitum.

\section{Ethical Statement}

We followed the ARRIVE (Animal Research: Reporting of in vivo Experiments) Guidelines for animal investigation. Mice were randomized, and the measurement of parameters was blinded to treatment groups. A research coordinator was aware of the animal treatment group. The Committee for Animal Care and Investigation of Mie University approved (Approval No:24-50) the experimental procedures. The study was performed according to the institutional guidelines of Mie University and following internationally approved laboratory animal care principles published by the National Institute of Health (https://olaw. nih.gov/).

\section{Induction of DM}

DM was induced by intraperitoneal injection of $40 \mathrm{mg} / \mathrm{kg}$ body weight of streptozotocin (STZ; Sigma, St. Louis, MO, USA) dissolved in $200 \mu \mathrm{L}$ of physiological saline for five consecutive days. ${ }^{22}$ STZ is a pancreatic $\beta$-cellspecific cytotoxin that induces apoptosis of $\beta$-cells by increasing oxidative stress and mitochondrial dysfunction. ${ }^{23}$ Non-diabetic control mice received physiological saline. Mice with DM were allocated to two treatment groups: an $\mathrm{STZ}+\mathrm{ND}$ group $(\mathrm{n}=6)$ that received intraperitoneal STZ and normal diet (ND) and an STZ + LMD group $(\mathrm{n}=7)$ that received intraperitoneal $\mathrm{STZ}$ and limonite diet (LMD). The non-diabetic control mice comprised a $\mathrm{SAL}+\mathrm{ND}$ group $(\mathrm{n}=4)$ that received intraperitoneal saline and a normal diet and a SAL+LMD group $(n=6)$ that received intraperitoneal saline and a 5\% limonite diet. Four mice were allocated per cage. All mouse groups were followed for eight weeks. We performed an intraperitoneal glucose tolerance (IPGT) test on the 7th week and an insulin secretion test on the 8th week after starting STZ injection. On the last day of the 8th week, the mice were euthanized by an overdose of isoflurane followed by exsanguination by cardiac puncture.

\section{Induction of Metabolic or Insulin Resistance Syndrome}

Mice with metabolic syndrome were generated by administering a high-fat diet with $60 \%$ calories from fat (Clea, Shizuoka, Japan; https://www.clea-japan.com/en/products/ general diet/item d0080). There were three experimental groups. A group of mice $(\mathrm{n}=16)$ that received a high-fat diet (HFD) for five weeks were re-allocated from the 6th week into two treatment groups: an HFD group $(n=8)$ that continued receiving the high-fat diet for additional 15 weeks and an HFD+LM group $(\mathrm{n}=8)$ that received a highfat diet containing $5 \%$ limonite for additional 15 weeks. Mice with no metabolic syndrome receiving a normal diet (ND group; $\mathrm{n}=8$ ) for 20 weeks were the control group. Four mice were allocated per cage. We measured glucose or insulin concentrations on the 5th, 6th, 14th, and 20th week and performed intraperitoneal glucose tolerance (IPGT) test on the 14th week after starting the experiment.

\section{Evaluation of DM Parameters}

The levels of fasting blood glucose were measured in all groups during the follow-up. The insulin levels were also measured, and the Homeostatic Model Assessment of Insulin Resistance (HOMA-IR) was calculated in the metabolic syndrome and control groups. The intraperitoneal glucose tolerance (IPGT) test was performed after $16 \mathrm{~h}$ of fasting by intraperitoneal injection of glucose $(1 \mathrm{~g} /$ $\mathrm{kg}$ mouse body weight). Insulin secretion test was performed in the STZ-induced DM and control groups after $16 \mathrm{~h}$ of fasting by intraperitoneal injection of $3 \mathrm{~g} / \mathrm{kg}$ mouse body weight of glucose.

\section{Tissue Preparation and Staining}

All mice groups were sacrificed by an overdose of the anesthetic isoflurane followed by exsanguination by cardiac puncture. After euthanasia, the pancreas and the liver were dissected, dehydrated, embedded in paraffin, cut into $3-\mu \mathrm{m}$ thick sections, and prepared for hematoxylin and eosin (H\&E) stain. A researcher that was blinded to the treatment group measured the areas of pancreatic islets stained with H\&E using an Olympus BX50 microscope with a plan objective and an Olympus DP70 digital camera (Tokyo, Japan) and WinRoof image processing software (Mitani Corporation, Fukui, Japan). A portion of liver tissue was excised and homogenized in phosphatebuffered saline containing a cocktail of proteinase inhibitors (Nacalai Tesque, Kyoto, Japan) to measure iron levels.

\section{Immunohistochemistry}

Immunofluorescence staining of insulin and glucagon in pancreatic islets was performed at Morphotechnology Co., Ltd (Sapporo, Japan) with specific antibodies in SAL/ND $(\mathrm{n}=3), \mathrm{SAL} / \mathrm{LMD}(\mathrm{n}=3), \mathrm{STZ} / \mathrm{ND}(\mathrm{n}=4)$, and STZ/ 
LMD $(n=4)$ groups. The stained preparations were then observed under a fluorescence microscope BX53, and microphotographs were blindly taken using a DP73 digital camera with a DP controller software (Olympus, Tokyo, Japan). The insulin and glucagon stained areas were quantified using WinRoof image processing software (Mitani Corporation, Fukui, Japan) as previously described. ${ }^{21}$

\section{Evaluation of Apoptosis in Pancreatic Islets}

Apoptosis of pancreatic islets was evaluated using a terminal deoxynucleotidyl transferase dUTP nick and labeling (TUNEL) staining kit (Chemicon International, Temecula, CA, USA). TUNEL-positive areas cells were quantified in SAL/ND $(n=3)$, SAL/LMD $(n=3), S T Z / N D$ $(n=4)$, STZ/LMD $(n=4)$ using WinRoof image processing software (Mitani Corporation, Fukui, Japan) as previously described. ${ }^{24}$

\section{Biochemical Analysis}

The blood glucose level was measured by the glucose oxidase method and insulin using a kit from ALPCO Diagnostics (Salem, NH, USA). The interleukin (IL)12 p70, IL-6, tumor necrosis factor (TNF)- $\alpha$ and monocytechemoattractant protein (MCP)-1 levels were measured using commercially available immunoassay kits from BD Bioscience (San Jose, CA, USA). Markers of liver injury were assessed by measuring the plasma levels of aspartate aminotransferase (AST) and alanine aminotransferase (ALT), using a kit (Wako Transaminase CII-Test kit) from Wako Pure Medical (Tokyo, Japan). ${ }^{25}$ The iron levels were measured using a commercial kit from Metallogenics Co. Ltd. (Chiba, Japan). Homeostasis model assessment for insulin resistance (HOMA-IR) was calculated using the following formula: HOMA-IR $=$ [fasting insulin $(\mu \mathrm{U} / \mathrm{mL})$ $\times$ fasting glucose $(\mathrm{mmol} / \mathrm{L})] / 22.5 .^{26,27}$ Measurements of parameters or markers in the samples were performed at the same time to decrease variability.

\section{Cell Culture in the Presence of Limonite}

Caco-2 cells were cultured up to sub-confluence, and after serum starvation, they were treated with limonite (LM) for $1 \mathrm{~h}$ before adding $100 \mathrm{ng} / \mathrm{mL}$ of lipopolysaccharide (LPS). After culturing for $24 \mathrm{~h}$, the cell supernatants were collected for biochemical analysis, and the cells were harvested for gene expression analysis.

\section{Analysis of Gene Expression}

The total RNA from cells was extracted with Trizol Reagent (Invitrogen, Carlsbad, CA, USA), reversetranscribed using oligo-dT primers, and the DNA was amplified by PCR using the Superscript Pre-amplification system kit (Invitrogen). Supplementary Table 1 describes primer sequences.

\section{Isolation and Analysis of Spleen Cells}

During euthanasia of mice with DM, spleens were removed, immediately incised, and minced with scissors into $2-3 \mathrm{~mm}$ pieces and incubated for $30 \mathrm{~min}$ at $37^{\circ} \mathrm{C}$ in RPMI medium containing $0.5 \mathrm{mg} / \mathrm{mL}$ collagenase (SigmaAldrich, St. Louis, MO, USA) and $10 \mu \mathrm{g} / \mathrm{mL}$ DNAase (Sigma-Aldrich). Single-cell suspensions were then obtained by grinding and filtering the tissues through a $70 \mu \mathrm{m}$ diameter nylon mesh (BD Bioscience, San Jose, CA, USA). Spleen cells were analyzed by flow cytometry (FACScan, BD Biosciences, Oxford, UK).

\section{Flow Cytometry Analysis}

Antibodies used in the flow cytometry analysis were as follows: fluorescein isothiocyanate (FITC)-labeled antimouse Ly-6G/Ly-6C (Gr-1; clone RB6-8C5) rat IgG2bк, phycoerythrin (PE)-labeled anti-mouse F4/80 (clone CIA31) rat $\operatorname{IgG} 2 \mathrm{~b} \kappa, \mathrm{PE} / \mathrm{Cy} 5$-labeled anti-mouse CD11c (clone N418) hamster IgG, FITC-labeled anti-mouse CD3 $\varepsilon$ (clone 145-2C11) hamster IgG, PE/Cy5-labeled anti-mouse CD45R/B220 (clone RA3-6B2) rat IgG2aк, FITC-labeled anti-mouse CD25 (clone PC61) rat IgG1 $\lambda$, PE-labeled antimouse CD8a (clone 53-6.7) rat IgG2aא, and PE/Cy5labeled anti-mouse CD4 (clone GK1.5) rat IgG2bк were from BioLegend, Inc. (San Diego, CA, USA). PE-labeled anti-mouse NK1.1 (clone PK136) mouse IgG2ak, biotinFasL (clone MFL3) Armenian hamster IgG2, FITCstreptavidin and FITC-annexin $\mathrm{V}$ were from $\mathrm{BD}$ Pharmingen (San Diego, CA, USA). Monocytes/macrophages were defined as $\mathrm{SSC}^{\mathrm{hi}} \mathrm{F} 4 / 80^{\mathrm{hi}} \mathrm{Gr}-1 \mathrm{lo}$ population, granulocytes as $\mathrm{SSC}^{\text {hi }} \mathrm{Gr}-1^{\text {hi }}$ cells and dendritic cells as SSC ${ }^{\text {lo }}$ F4/80-cells. B cells, T cells, NK cells, NKT cells were defined as $\mathrm{SSC}^{\text {lo }} \mathrm{CD} 45 \mathrm{R}+, \mathrm{SSC}^{\mathrm{lo}} \mathrm{CD} 3 \varepsilon+\mathrm{NK} 1.1-$, $\mathrm{SSC}^{\mathrm{lo}} \mathrm{CD} 3 \varepsilon+\mathrm{NK} 1.1+$, and $\mathrm{SSC}^{\mathrm{lo}} \mathrm{CD} 3 \varepsilon+\mathrm{NK} 1.1+$, respectively. CD4 T cells (CD4+CD8-), CD8 T cells (CD4-CD8 + ), and regulatory $\mathrm{T}$ cells $(\mathrm{CD} 4+\mathrm{CD} 8-\mathrm{CD} 25+)$ were also counted. Values represent the percentage of the nonparenchymal cells in each organ. 


\section{Micro-Computed Tomography of the Liver}

Micro-computed tomography of the liver was performed with a micro-CT Latheta LCT-200 purchased from Hitachi Aloka Medical (Tokyo, Japan). After anesthesia with isoflurane inhalation, mice were placed in a prone position for data acquisition. ${ }^{28}$

\section{Analysis of the Gut Microbial Communities}

A fecal sample was collected from each mouse at the end of the experiment for DNA extraction. DNA was purified using AMPureXP (Beckman Coulter Inc, Brea, CA, USA) according to the manufacturer's instructions, and DNA concentration was quantified using the NanoDrop ${ }^{\circledR}$ ND1000 Spectrophotometer (Nanodrop Technologies, Wilmington, DE, USA) and then used for subsequent analysis. For sequencing the small subunit ribosomal RNA hypervariable regions, forward (341F: 5'-TCG TCG GCA GCG TCA GAT GTG TAT AAG AGA CAG CCT ACG GGN GGC WGC AG-3') and reverse (806R: 5'GTC TCG TGG GCT CGG AGA TGT GTAT AAG AGA CAG GGA CTA CHV GGG TTC TAA T-3') primers targeting the hypervariable $\mathrm{V} 3-\mathrm{V} 4$ regions were used to prepare amplicons of the 16S rRNA gene as previously described. ${ }^{29} \mathrm{PCR}$ amplification conditions were: denaturation at $94^{\circ} \mathrm{C}$ for $1 \mathrm{~min} ; 28$ cycles of $98^{\circ} \mathrm{C}$ for $10 \mathrm{~s}, 50^{\circ} \mathrm{C}$ for $15 \mathrm{~s}, 68^{\circ} \mathrm{C}$ for $15 \mathrm{~s}$; and hold at $4^{\circ} \mathrm{C}$. Adaptation of the amplicons with Illumina sequencing adapters and dualindex barcode sequences was carried out using a kit (Nextera XT Index; Illumina Inc., San Diego, CA, USA), and then the amplicons were purified (AMPure XP Beads; Beckman Coulter Inc., Brea, CA, USA) according to the manufacturer's instructions. Sequencing was performed using an Illumina Miseq platform (Illumina Inc.) at Takara Bio Facility (Kusatsu, Shiga, Japan). For microbial community analysis, the nucleotide sequence clustering program CD-HIT-OTU was used for quality filtering, assembling, and operational taxonomic units (OTU) clustering at $97 \%$ sequence similarity. ${ }^{30}$ Ribosomal Database Project (RDP) classifiers within the bioinformatic QIIME (Quantitative Insights Into Microbial Ecology) pipeline and the Greengenes reference database were used for making an OTU chart. ${ }^{31-33}$

\section{Statistical Analysis}

The results are the mean \pm standard deviation (S.D.) of the means unless otherwise specified. Data collected from all mice were included in the evaluation. The normal distribution of the variables was evaluated by the KolmogorovSmirnov test. The statistical difference between variables with normal distribution was calculated by unpaired $t$-test or by one-way analysis of variance with post hoc analysis using Tukey's test. The statistical difference between variables with skewed distribution was calculated by the Mann-Whitney $U$-test or by the Kruskal-Wallis analysis of variance with post hoc analysis using Dunn's test. The relationship between parameters was evaluated by Spearman correlation. Statistical analyses were done using the GraphPad Prism version 7.0 (GraphPad Software, San Diego, CA, USA). A p $<0.05$ was considered statistically significant.

\section{Results \\ Amelioration of DM in Mice Fed with Limonite Supplement}

Diabetic mice fed with a normal diet (STZ+ND) showed significantly decreased body weight and increased blood glucose levels compared to non-diabetic mice fed with a normal diet (SAL/ND) from the 2nd week after induction of DM with STZ. However, diabetic mice fed with limonite (STZ/LMD) had significantly increased body weight and decreased blood glucose levels compared to diabetic mice fed with a normal diet (STZ/ND) from the 4th week after induction of DM with STZ (Figure 1A and B). Consistent with these results, the IPGT test showed that diabetic mice receiving normal diet (STZ/ND) had significantly increased blood glucose levels after 15, 30, 60, and 120 minutes of glucose injection compared to nondiabetic mice receiving normal diet (SAL/ND) and after 15, 30, 60 and 120 minutes of glucose injection compared to diabetic mice fed with limonite diet (STZ/LMD). The area under the curve was also significantly lower in the STZ/LMD group than in the STZ/ND group (Figure 1C). During the insulin secretion test, the plasma concentration of insulin was significantly high in diabetic mice receiving limonite diet (STZ/LMD) 2 minutes after glucose administration compared to diabetic mice receiving a normal diet (STZ/ND) (Figure 1D). 
A

Time schedule for STZ-induced type 1 diabetes mellitus
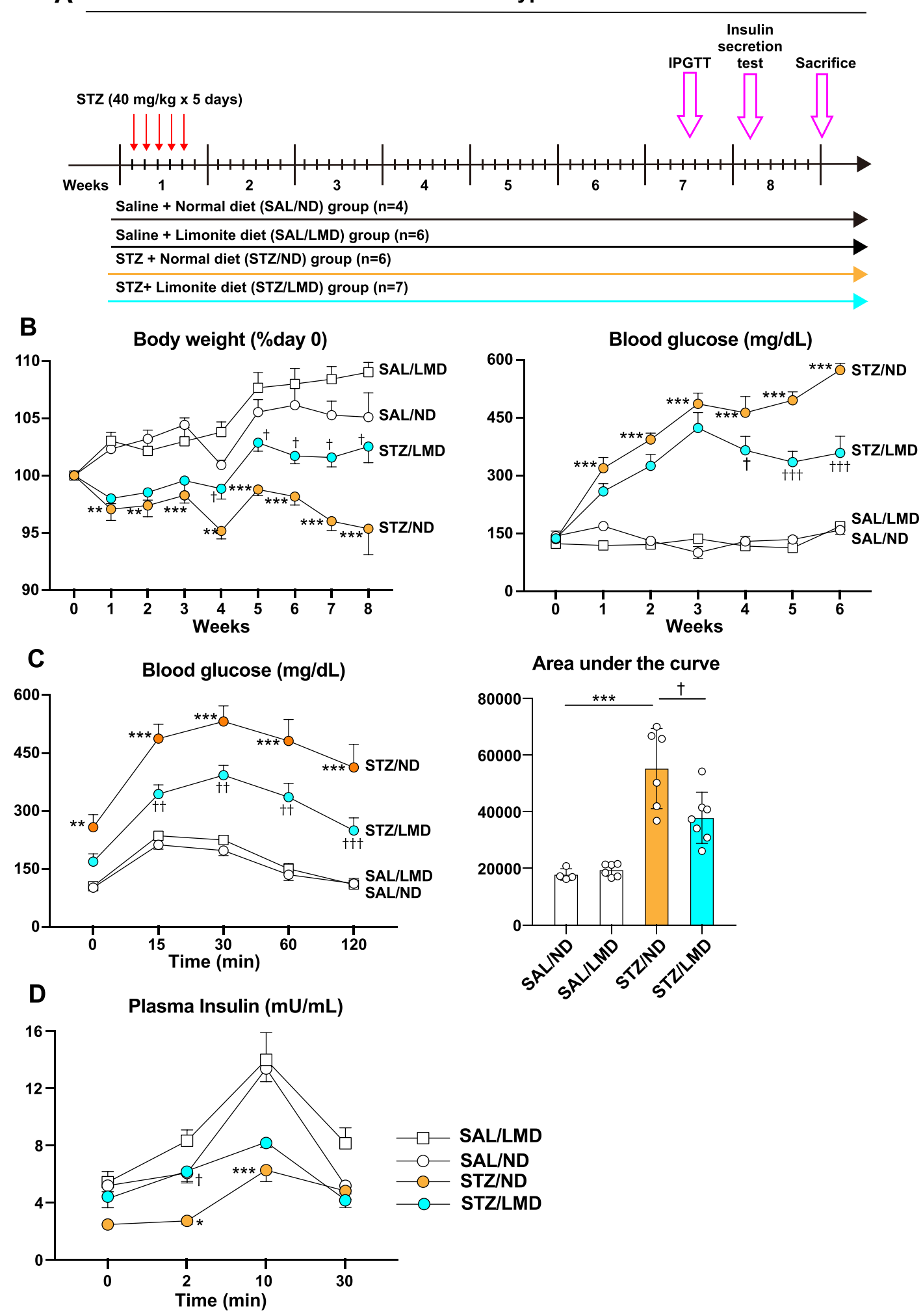

Figure I Amelioration of DM in mice fed with limonite supplement compared to control mice. (A) There were four treatment groups: SAL/ND group ( $\mathrm{n}=4$ ) treated with saline (SAL) and normal diet (ND); SAL/LMD group $(n=6)$ treated with saline and limonite diet $(L M D)$; STZ/ND group $(n=6)$ treated with streptozotocin and normal diet; STZ/LMD group $(n=7)$ treated with streptozotocin (STZ) and limonite diet. (B) Body weight and blood glucose levels were sequentially measured. Glucose level was measured by glucose oxidase. (C) An intraperitoneal glucose tolerance test was performed, and the area under the curve was measured. (D) An insulin secretion test was performed. Data are the means \pm S.D. Statistical analysis was performed by one-way ANOVA with Tukey's test. ${ }^{*} p<0.05$; ${ }^{* *} p<0.01$ and ${ }^{* * *} p<0.00$ I versus SAL/ND group. $\dagger p<0.05$, $\dagger \dagger p<0.01$ and $\dagger \dagger \dagger p<0.00$ I versus STZ/ND group. 


\section{Mice Receiving Limonite Supplement Have More Pancreatic Islet $\beta$ Cells}

Mice with DM fed with normal food (STZ/ND) have significantly more TUNEL-positive areas compared to non-diabetic mice fed with a normal diet (SAL/ND) and mice with DM fed with limonite (STZ/LMD) (Figure 2A and B). The total area stained positive for insulin was significantly decreased, and the glucagon-positive area was significantly increased in DM mice receiving normal diet (STZ/ND) compared to nondiabetic mice receiving normal diet (SAL/ND) and diabetic mice fed with limonite (STZ/LMD) (Figure 2C-E).

\section{Mice Receiving Limonite Supplements Show Normal Levels of Iron in Plasma and Liver Tissue}

The plasma and liver tissue levels of iron were not significantly different between diabetic mice fed with normal food (STZ/ND) and diabetic mice fed with limonite (STZ/ LMD) (Supplementary Figure 1). The plasma iron levels were significantly decreased in diabetic mice fed with normal food (STZ/ND) or limonite (STZ/LMD) compared to non-diabetic mice fed with normal food (SAL/ND) or limonite (SAL/LMD), respectively. The liver tissue levels of iron were not significantly different between groups (Supplementary Figure 1).

\section{Change of T Cell Population in Mice with DM Fed with Limonite}

The total spleen cells were isolated, and the percentage of each type of cell was evaluated by flow cytometry. The percentage of $\mathrm{T}$ cells and the percentage of $\mathrm{CD} 4^{+} \mathrm{CD} 25^{+}$ cells were significantly enhanced in mice with DM receiving limonite diet (STZ/LMD) compared to counterpart diabetic mice fed with normal diet (STZ/ND) (Supplementary Figure 2). There was no significant change in the percentage of monocytes/macrophages, dendritic cells, granulocytes, total lymphocytes, B cells, NK cells, NKT cells, $\mathrm{CD}^{+}{ }^{+}$cells $\mathrm{CD} 8^{+}$cells between the $\mathrm{STZ} /$ $\mathrm{ND}$ and STZ/LMD mouse groups.

\section{Remodeling of the Gut Microbiome in Mice with DM Fed with Limonite}

Analysis of the gut microbiome at the phylum level revealed a significant increase in Bacteroidetes and Tenericutes and a significant decrease in the bacterial community of Proteobacteria in diabetic mice receiving limonite compared to mouse counterpart fed with a normal diet (Figures 3A and B). Analysis at the genus level revealed a significant increase in the microbial population of Allobactum and a significant decrease in the population of Prevotella in diabetic mice receiving limonite compared to mouse counterparts fed with a normal diet (Figure 3C and D).

Correlation analysis showed that the bacterial communities of Bacteroidetes, Tenericutes, Allobactum, and Prevotella were significantly correlated with the serum concentration of insulin and the total number of $\mathrm{T}$ cells, $\mathrm{CD}^{+} \mathrm{T}$ cells, and $\mathrm{CD}^{+} / \mathrm{CD} 25^{+}$regulatory $\mathrm{T}$ cells (Supplementary Figure 3A and B).

\section{Amelioration of Metabolic Syndrome in Mice Receiving Limonite Supplement}

The body weight, fasting blood glucose, fasting blood insulin, and HOMA-IR were significantly increased in mice fed with a high-fat diet $(\mathrm{n}=16)$ at the end of the 5th week after starting the diet compared to mice receiving a standard caloric intake (Supplementary Figure 4A-C). Sixteen mice with metabolic syndrome $(n=16)$ were then allocated into a group fed with a high-fat diet (HFD group) and a group fed with HFD plus 5\% limonite (HFD+LM group) for additional 15 weeks before mouse euthanasia (Supplementary Figure 4A). Despite receiving an equivalent amount of calories, the bodyweight of mice fed with high calories containing limonite supplement (HFD+LM group) was significantly reduced compared to the group receiving no limonite supplement (HFD group) during the entire experimental protocol (Supplementary Figure 5A and B).

Mice fed with a high-fat diet showed significant compensatory hyperinsulinemia that was significantly decreased on the 6th and 14th week in mice receiving high-fat-diet supplemented with limonite (HFD+LM) (Figure 4A). Insulin resistance (HOMA-IR) was also significantly decreased in the group receiving limonite supplementation compared to the group fed with a high-fat diet alone (Figure 4A). After fasting and during the IPGT examination, the blood glucose levels were also low in mice treated with limonite supplements than counterparts receiving no limonite in the diet (Figure 4A and B).

\section{Inhibition of Liver Steatosis/Injury in Mice Receiving Limonite Supplement}

We found a significantly decreased liver fatty tissue area by CT study performed before sacrifice and reduced liver weight 


\section{A SAL/ND}

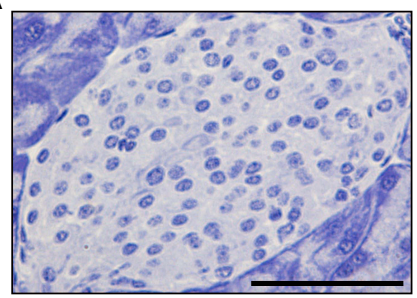

STZ/ND

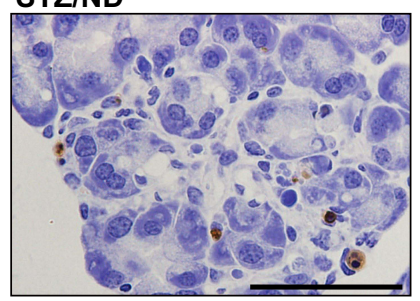

C SAL/ND

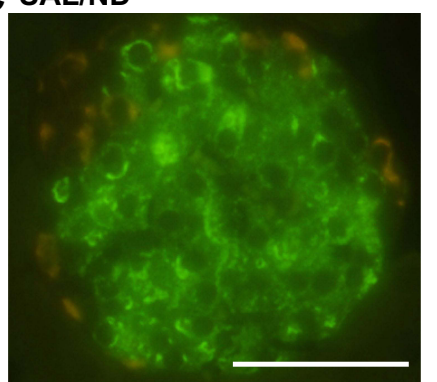

STZ/ND

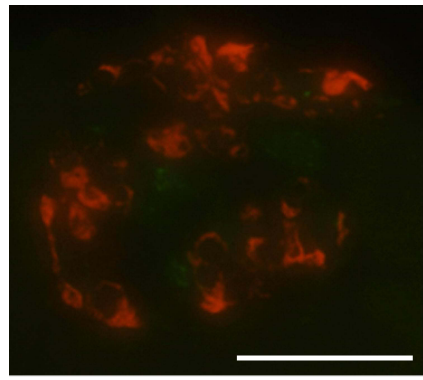

\section{SAL/LMD}

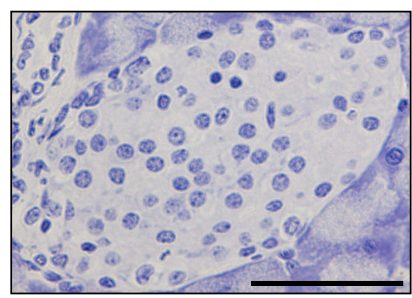

\section{STZ/LMD}

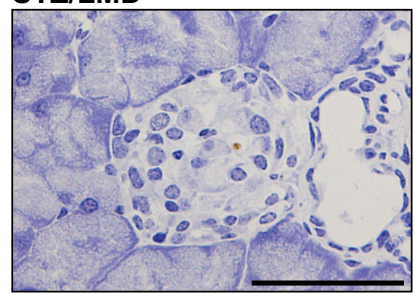

SAL/LMD

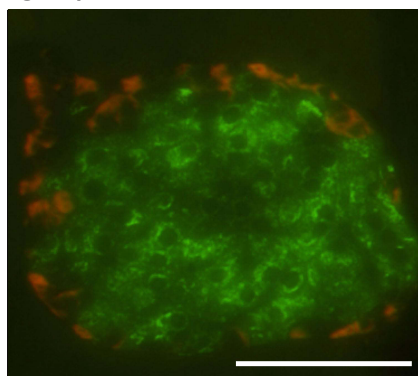

STZ/LMD

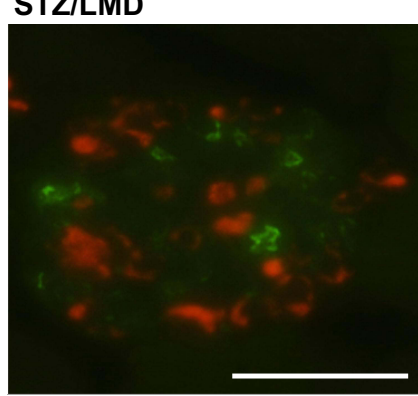

\section{B TUNEL (+) area}

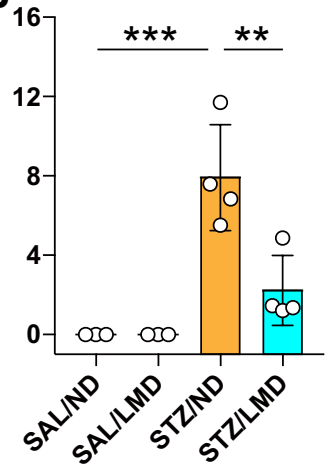

D Islet glucagon (+) area
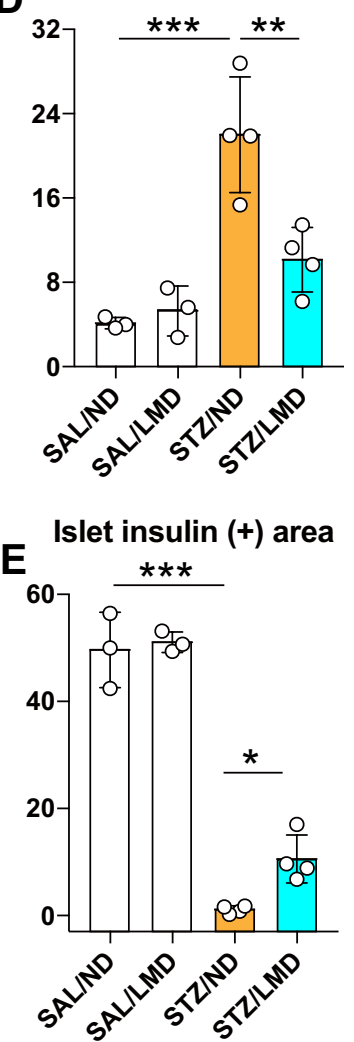

Figure 2 Diabetic mice fed with limonite showed increased islet $\beta$ cells compared to control mice. After euthanasia, the pancreatic tissues were incised, removed, and prepared for evaluating apoptosis and the areas of the pancreatic islet $\beta$-cells and $\alpha$-cells. The number of mice used for these experiments was as follows: SAL/ND group $(n=3)$ treated with saline (SAL) and normal diet (ND); SAL/LMD group $(n=3)$ treated with saline and limonite diet (LMD); STZ/ND group ( $n=4)$ treated with streptozotocin and normal diet; STZ/LMD group $(\mathrm{n}=4)$ treated with streptozotocin (STZ) and limonite diet. (A) Apoptosis was evaluated using a terminal deoxynucleotidyl transferase dUTP nick and labeling (TUNEL) staining. (B) The positive TUNEL staining areas were assessed using the WinRoof image processing software and compared between groups. (C) The areas of pancreatic islets positive for insulin and glucagon staining were evaluated using fluorescence microscopy. (D) The areas staining positive for glucagon (D) and insulin (E) were quantified using the WinRoof image processing software. Data are expressed as means \pm S.D. Scale bars indicate $50 \mu \mathrm{m}$. Statistical analysis was done using one-way ANOVA with Tukey's test. ${ }^{*} p<0.05$, ${ }^{* *} p<0.01$, *** $p<0.001$.

after euthanasia in mice treated with limonite supplement compared to untreated mice (Figure $5 \mathrm{~A}-\mathrm{C}$ ). H\&E staining of the liver tissue mice receiving limonite depicted a decrease in the fatty tissue area compared to untreated mice
(Figure 5D and E). The plasma levels of triglycerides and the plasma levels of liver enzymes (AST, ALT) were significantly reduced in mice fed with limonite supplement compared to mice fed with a high-fat diet alone (Figure 6A). 


\section{A Phylum}

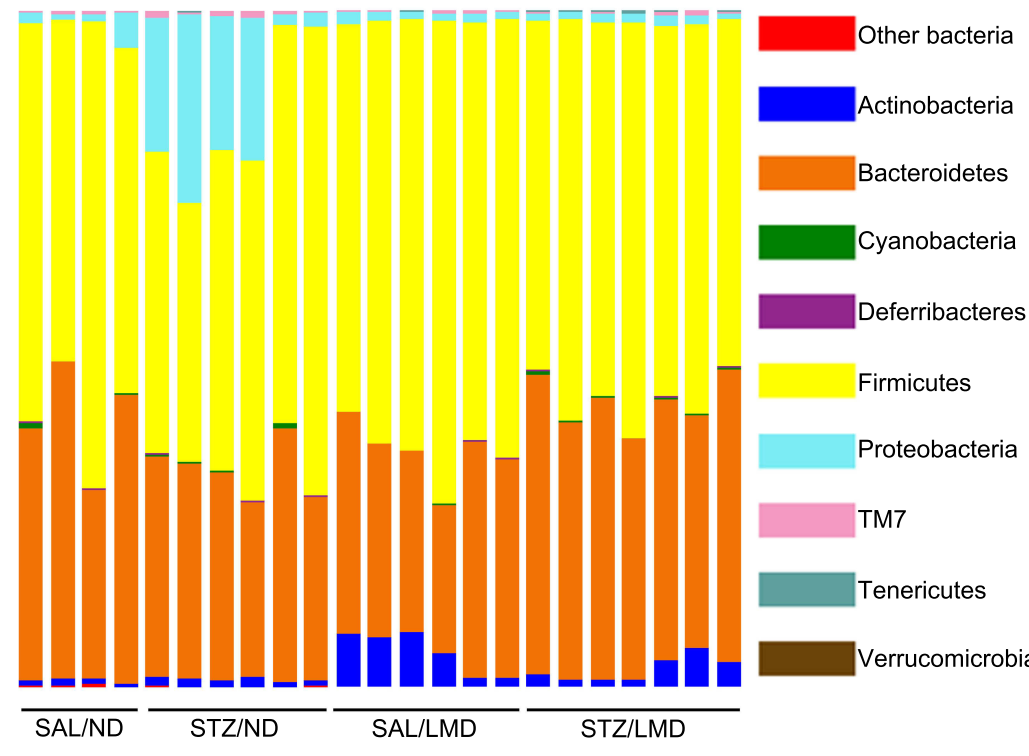

\section{Genus}
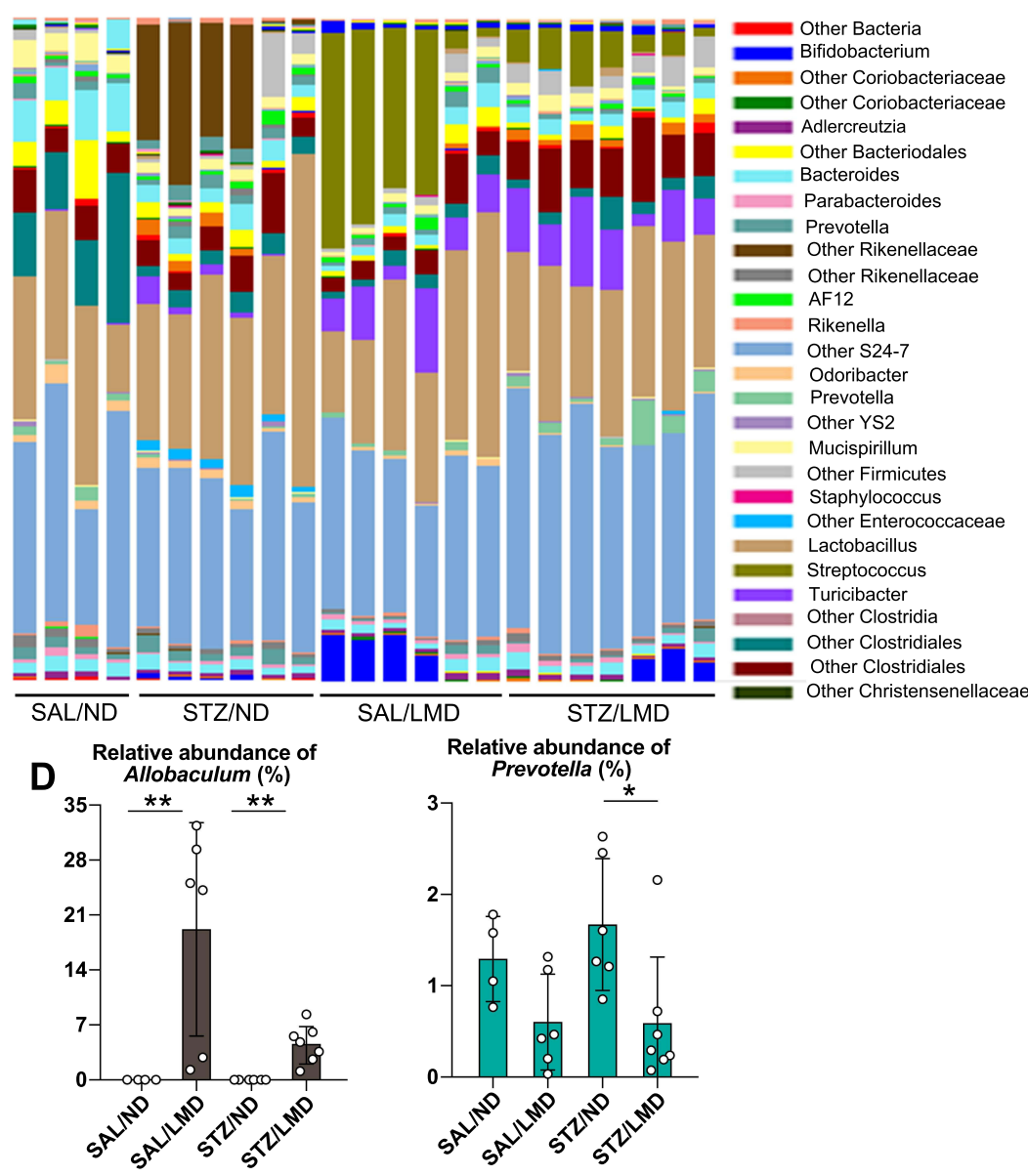

Other Rikenellaceae

AF12

Rikenella

Other S24-7

Odoribacter

Prevotella

Other YS2

Mucispirillum

Other Firmicutes

Staphylococcus

Other Enterococcaceae

Lactobacillus

Streptococcus

Turicibacter

Other Clostridiales

Other Clostridiales

Other Clostridiales

SAL/LMD STZ/LMD

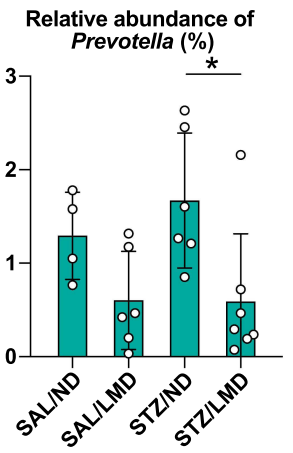

\section{Relative abundance of} B Proteobacteria (\%)

Relative abundance of Bacteroidetes (\%)
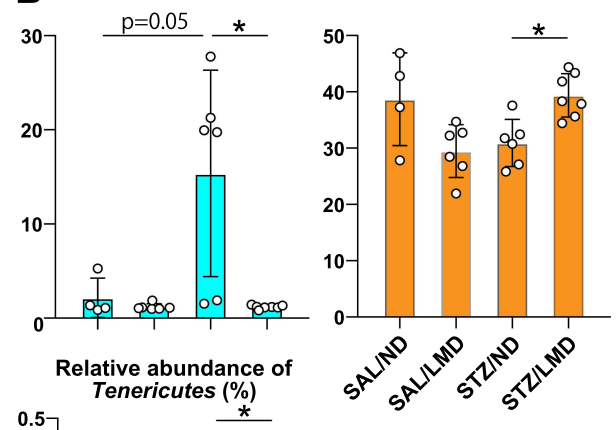
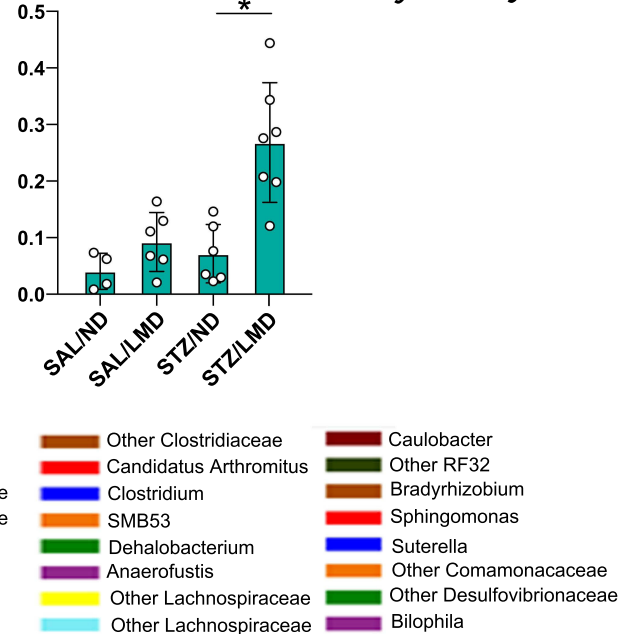

-

Clostridium

Coprococcus

Dorea

Roseburia

Ruminococcus

Other Peptococcacea

Other Ruminococcae

ovibrio

Flexispira

Other Ruminococcacea

Helicobacter

Other Ruminococcaceae

Butyricicoccus

Oscillospira

Other Enterobacteriaceae

Ruminococcus

Other Mogibacteriacea

Other Erysipelotrichaceae

Other Erysipelotrichaceae

Allobaculum

Clostridium

Coprobacillus

Other Christensenellaceae $=$ Other Proteobacteria

Figure 3 Remodeling of the gut microbiome in mice with DM fed with limonite supplement. A fecal sample was collected from each mouse for DNA extraction, and primers targeting the hypervariable V3-V4 regions were used to amplify the I6S rRNA gene by polymerase chain reaction. Sequencing was performed using an Illumina Miseq platform and microbial community analysis using a nucleotide sequence clustering program as described under Materials and Methods. The gut microbiome was evaluated in all mice from each group: SAL/ND group $(n=4)$ treated with saline $(S A L)$ and normal diet (ND); SAL/LMD group $(n=6)$ treated with saline and limonite diet $(L M D)$; STZ/ND group $(n=6)$ treated with streptozotocin and normal diet; STZ/LMD group $(n=7)$ treated with streptozotocin (STZ) and limonite diet. An evaluation was performed at phylum $(\mathbf{A}$ and $\mathbf{B})$ and genus $(\mathbf{C}$ and $\mathbf{D})$ levels. Data are the means \pm S.D. Statistical analysis was performed by Kruskal-Wallis ANOVA with Dunn's test. * $<<0.05$; ** $<<0.0$ I. 
A Blood glucose (mg/dL)

$6^{\text {th }}$ week of limonite therapy

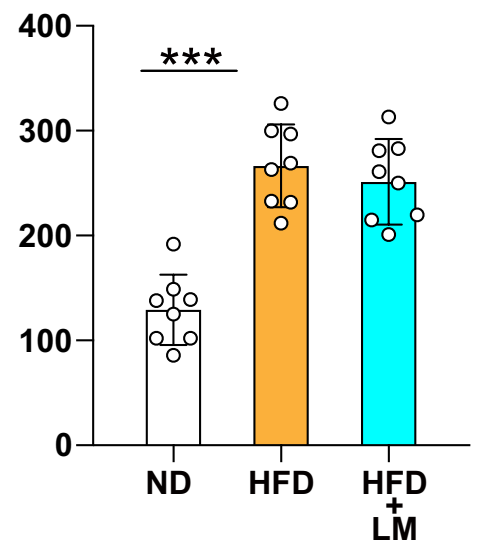

Blood glucose (mg/dL) $14^{\text {th }}$ week of limonite therapy

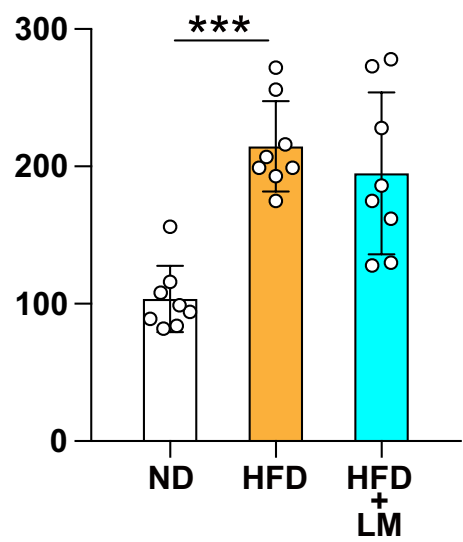

Blood Insulin $(\mu \mathrm{U} / \mathrm{mL})$ $6^{\text {th }}$ week of limonite therapy

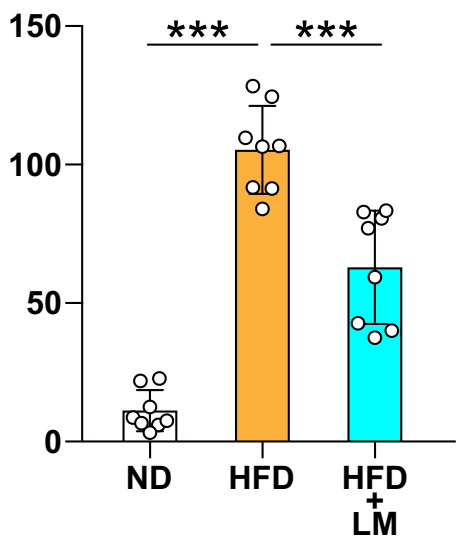

Blood insulin ( $\mu \mathrm{IU} / \mathrm{mL}$ ) $14^{\text {th }}$ week of limonite therapy

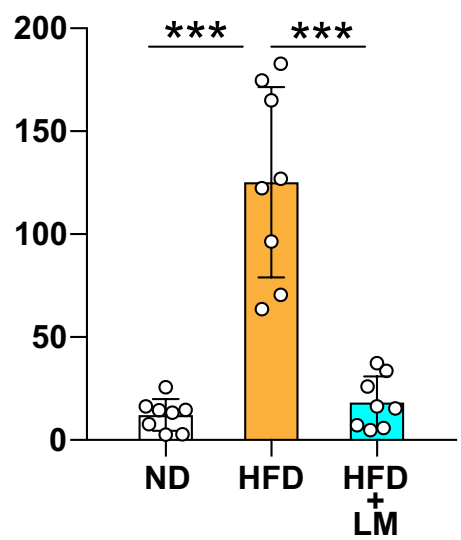

HOMA-IR

$6^{\text {th }}$ week of limonite therapy

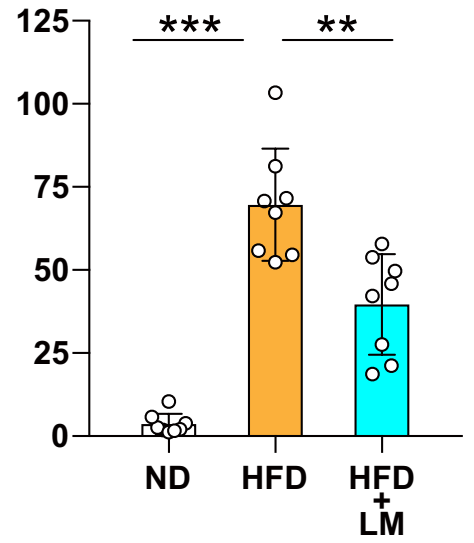

Blood insulin/glucose $14^{\text {th }}$ week of limonite therapy

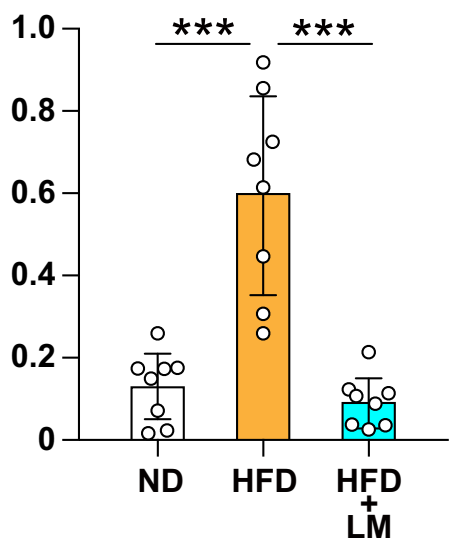

Area under the currve $8^{\text {th }}$ week of limonite therapy

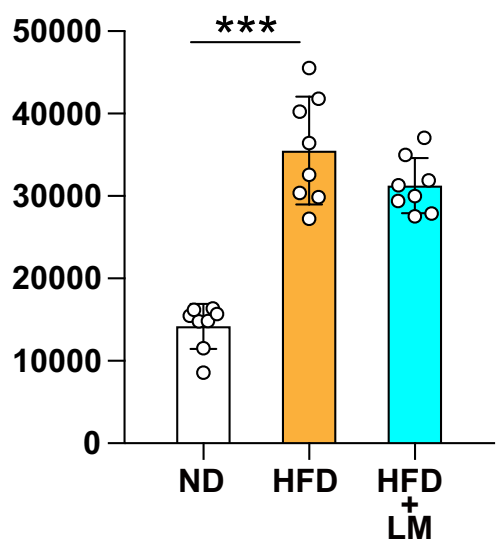

Figure 4 Amelioration of insulin resistance in mice receiving limonite supplement compared to control mice. (A) Mice received a high-fat diet (HFD, $n=8)$, a high-fat diet with limonite supplement (HFD+LM, $n=8$ ), or a normal diet (ND, $n=8)$. The levels of fasting blood glucose and insulin were measured on the 6th and I4th weeks after starting therapy with limonite. The Homeostasis Model Assessment for Insulin Resistance (HOMA-IR) was calculated on the 6th, and the blood insulin/glucose ratio was calculated on the 14th week after starting therapy with limonite. Data are the means \pm S.D. (B) Intraperitoneal glucose tolerance test and calculation of the area under the curve were performed on the 8th week after starting limonite supplement. Data are the means \pm S.E. Statistical analysis was performed by one-way ANOVA with Tukey's test. $* * p<0.05, * * *<<0.001$. 
A

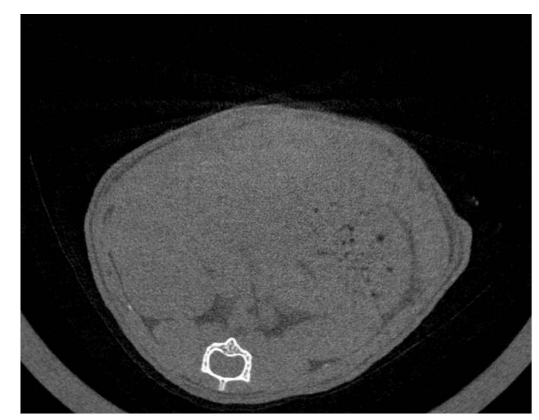

HFD

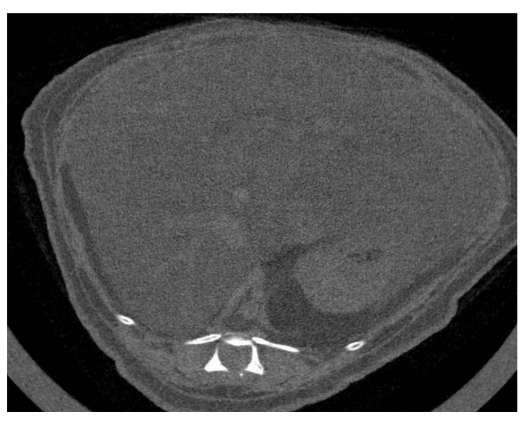

HFD + LM

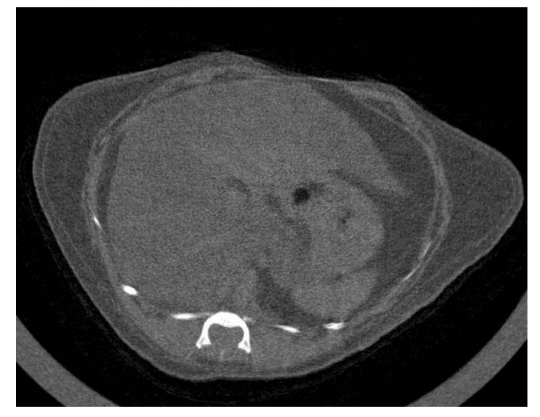

D

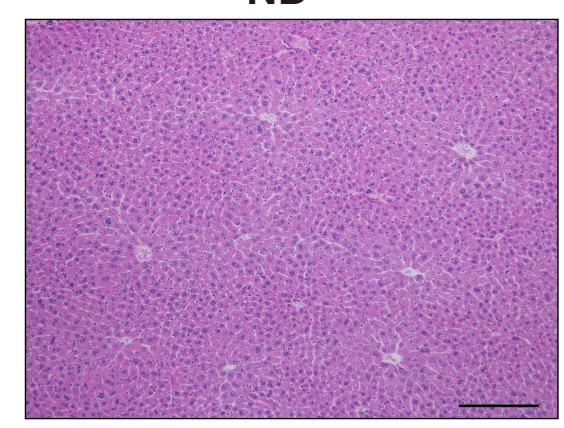

HFD

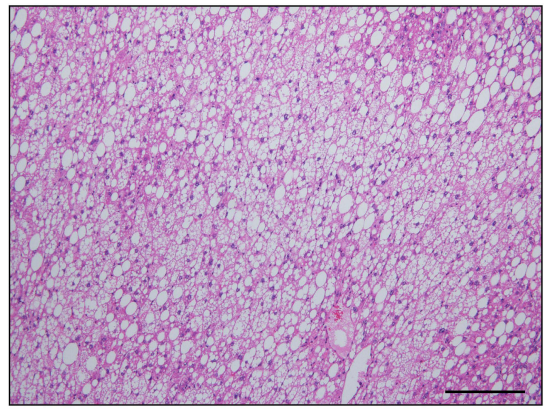

HFD + LM

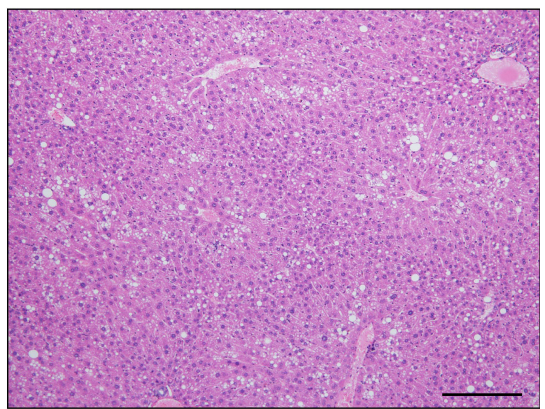

B CT liver fatty area (\%)

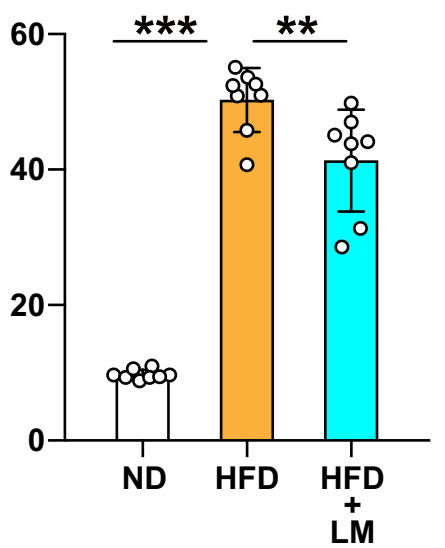

C Liver weight (g)

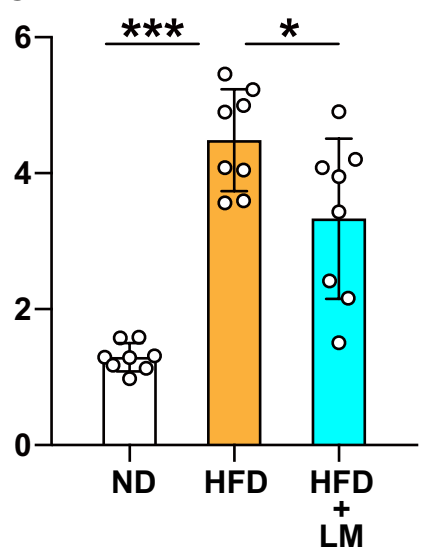

E Fatty tissue area (\%)

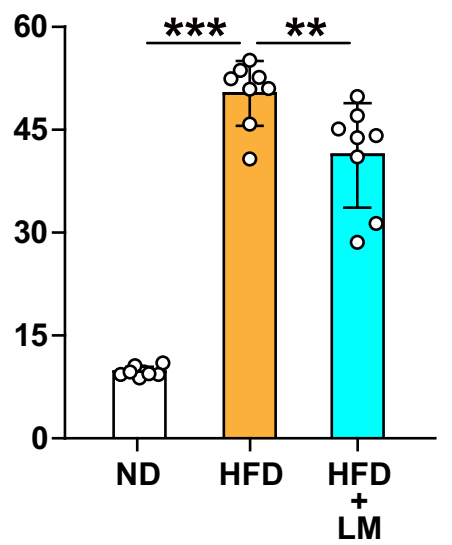

Figure 5 Inhibition of liver steatosis in mice receiving limonite supplement compared to control mice. Mice received a high-fat diet (HFD, $\mathrm{n}=8$ ), a high-fat diet with limonite supplement (HFD+LM, $n=8)$, or a normal diet (ND, $n=8)$. (A) Computed tomography of the liver was performed in each mouse group as described under Materials and Methods. (B) Quantification of the adipose tissue area was performed using the WinRoof image processing software. (C) Measurement of liver weight in each mouse group after euthanasia by an overdose of anesthesia. (D) Hematoxylin \& eosin staining of liver tissue in each group. Scale bars indicate $100 \mu \mathrm{m}$. (E) Quantification of the adipose areas using the WinRoof image processing software. Data are the means \pm S.D. Statistical analysis was performed by one-way ANOVA with Tukey's test. * $<<0.05$, ** $<<0.0$ I, $* * * p<0.001$. 

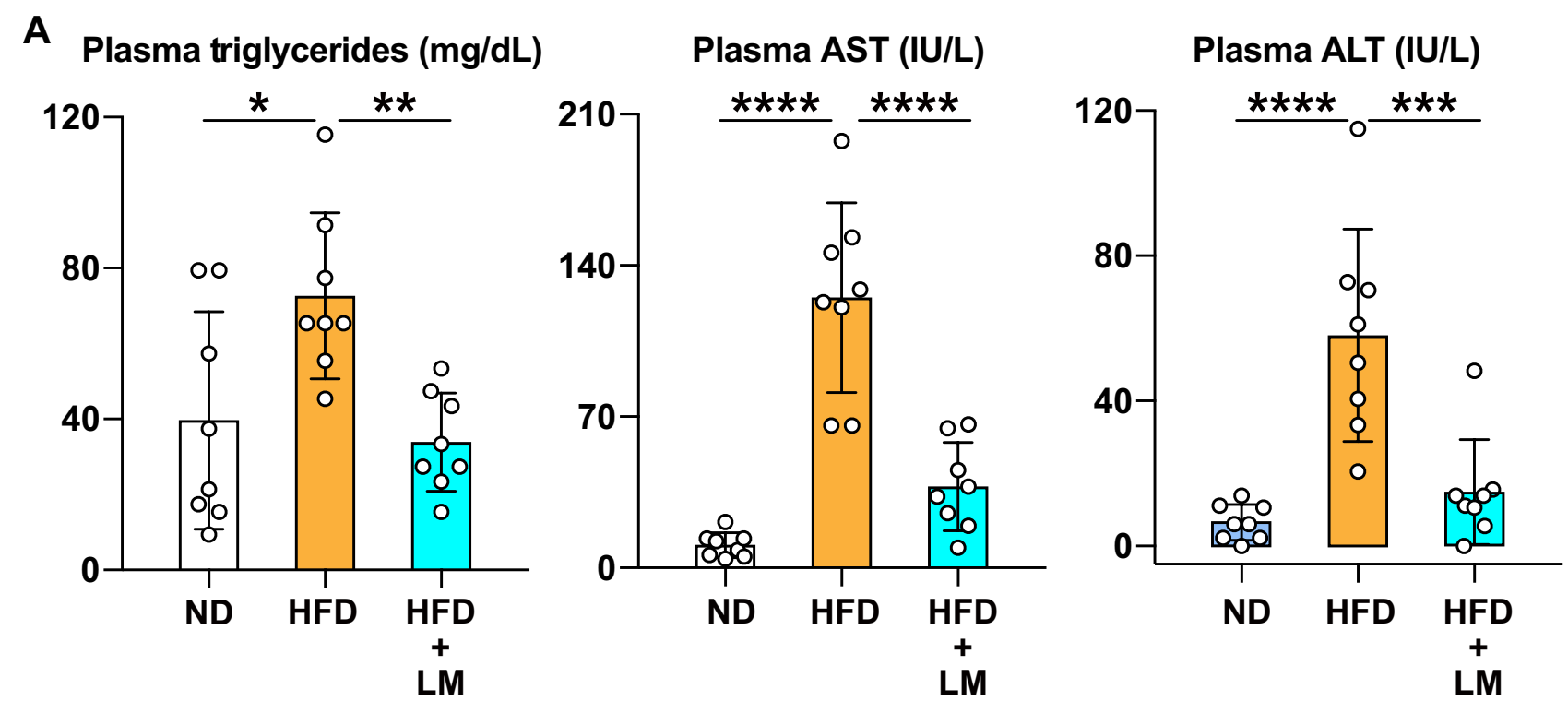

\section{B Plasma MCP-1 (pg/mL)}
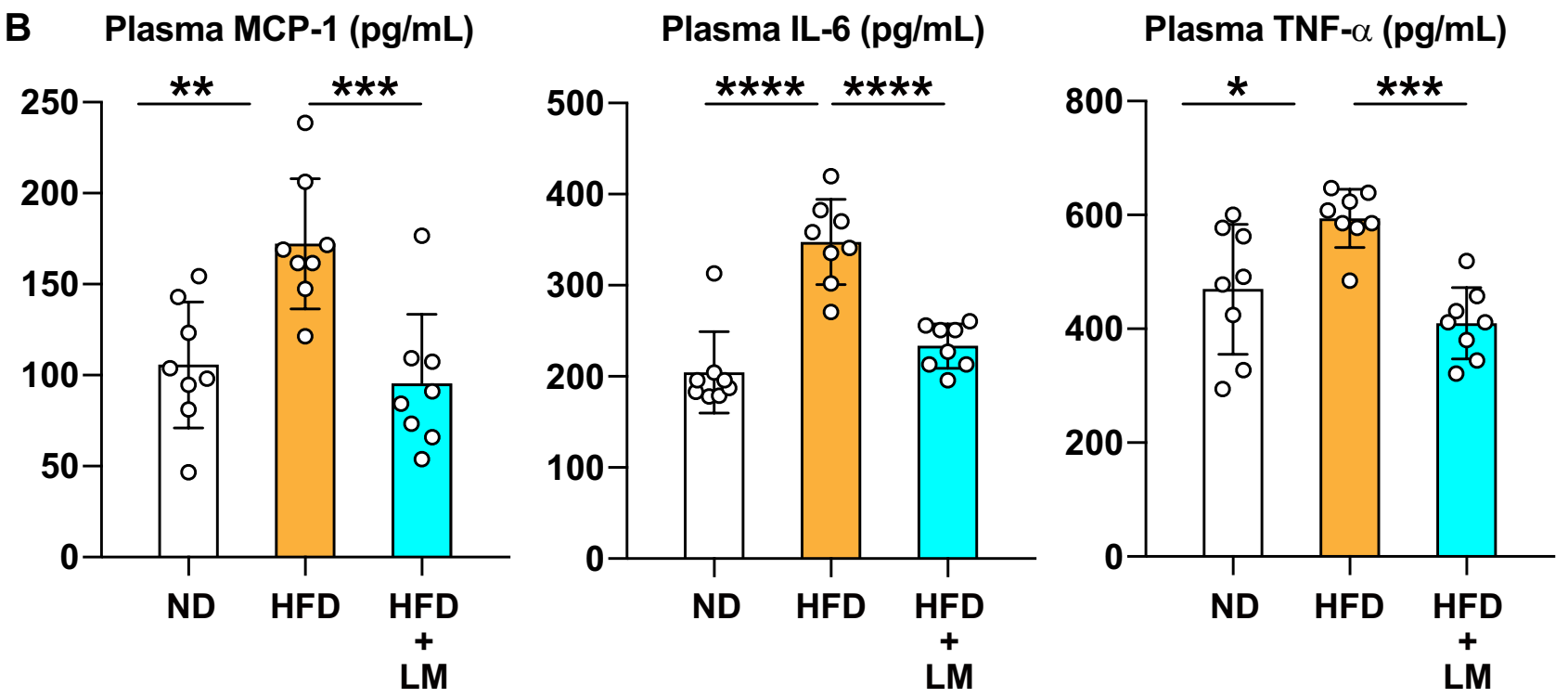

Figure 6 Inhibition of liver injury and systemic inflammation in mice receiving limonite compared to control mice. Mice received a high-fat diet (HFD, $n=8)$, a high-fat diet with limonite supplement (HFD+LM, $n=8)$, or a normal diet $(N D, n=8)$. (A) The levels of triglycerides, aspartate aminotransferase (AST), and alanine aminotransferase $(A L T)$ were measured using commercially available kits. (B) Monocyte chemoattractant protein-I (MCP-I), interleukin-6 (IL-6), and tumor necrosis factor- $\alpha$ (TNF- $\alpha$ ) were measured using commercially available immunoassay kits. Data are the means \pm S.D. Statistical analysis was performed by one-way ANOVA with Tukey's test. * $<0.05$, $* * p<0.01, * * * p<0.001, * * * * p<0.0001$.

Mice with Metabolic Syndrome Fed with Limonite Supplement Had Low Circulating Levels of Inflammatory Cytokines

We collected blood by cardiac puncture under profound anesthesia. The blood was centrifuged to separate plasma from the cell fraction, and the concentration of inflammatory cytokines was measured in plasma in each group of mice. The plasma concentrations of MCP-1, IL-6, and $\mathrm{TNF} \alpha$ were significantly increased in mice receiving
HFD alone compared to mice fed with standard baits. However, mice fed with HFD plus limonite supplements significantly decreased plasma concentrations of MCP1, IL-6, and TNF $\alpha$ compared to mice that received HFD alone (Figure 6B). The plasma concentration of iron (Fe) was significantly increased in mice fed with HFD compared to mice fed with standard food (ND group). However, despite the high iron content of limonite, the plasma and liver tissue levels of iron $(\mathrm{Fe})$ were not 
significantly different between the HFD and HFD+LM groups (Supplementary Figure 6A).

\section{The Beneficial Effect of Limonite is Independent of GLP-I}

GLP-1 is an incretin that reduces blood glucose levels by increasing the secretion of insulin. We found that the plasma concentration of GLP-1 was significantly increased in mice fed with a high-fat diet compared to mice receiving standard food. However, the administration of limonite supplement in the diet significantly decreased the concentration of plasma GLP-1 compared to a standard food (Supplementary Figure 6B).

\section{Remodeling of the Gut Microbiome in Mice with Metabolic Syndrome Fed with Limonite Supplement}

Analysis of the gut microbiome at the order level revealed a significant increase in the bacterial population of Coriobacteriales and Clostridiales and a significant decrease in Turicibacteriales, at the family level, a significant increase in Lachnospiraceae, and at the genus level, a significant increase in the bacterial community of Oscillospira in diabetic mice receiving a high-fat diet with limonite supplement (HFD+LM) compared to mice fed with high-fat diet (HFD) alone (Figure 7A-F).

Correlation analysis showed that the bacterial communities of Clostridiales and Turicibacteriales are significantly correlated with the plasma levels of IL- 6 , TNF- $\alpha$, aspartate aminotransferase (AST), triglycerides, the values of HOMA-IR, and the insulin/glucose ratio (Supplementary Figure 7A and B). Turicibacteriales, Lachnospiraceae, and Oscillospira were significantly correlated with the degree of fatty liver, plasma levels of TNF- $\alpha$ and the insulin/glucose ratio. Coriobacteriales were significantly correlated with the plasma levels of IL-6, AST, triglycerides, and the insulin/glucose ratio (Supplementary Figure 7A and B).

\section{Limonite Downregulates Inflammatory Cytokine Secretion from Intestinal Cells}

To evaluate the direct influence of limonite on intestinal cells' pro-inflammatory activity, we cultured Caco-2 cells in vitro in the presence or absence of limonite and measured inflammatory cytokines' expression. The relative mRNA expression of TNFa, IL-12p40, IL-12p35, and IL-6, and the secretion of IL-6 in the culture supernatant were significantly decreased in cells cultured in the presence of limonite compared to controls (Supplementary Figure 8).

\section{Discussion}

This study shows that limonite supplements in diet improve glucose metabolism abnormalities, induce remodeling of the gut microbiome, and promote antiinflammatory activity in DM and metabolic syndrome.

Limonite is a natural ore formed when the mineral-rich underground water is oxidized in the ground surface during Mount Aso's eruption in Japan. ${ }^{11}$ The raw limonite is collected from the volcanic caldera and processed for three years before its industrial application. The raw limonite processing steps include weathering, drying, pulverization sieving, and sterilization. ${ }^{11}$ The processed limonite is currently used for absorption of harmful and offensive gases (ammonia, hydrogen sulfide) from municipal and industrial waste materials, for soil activation to enhance productivity in agriculture, for preventing contamination of ponds, fountains, and rivers by algae and water blooms, and for improving the breeding of livestock (pig, cow). However, no study reports the beneficial effects of limonite supplements in vivo and under pathological conditions. In the present study, we developed two models of disease associated with abnormal glucose metabolism and evaluated the influence of limonite supplements. Oral administration of limonite supplements significantly reduced hyperglycemia, improved insulin secretion and body weight, significantly inhibited apoptosis of insulinsecreting cells in mice with DM, significantly reduced liver steatosis, and improved insulin resistance and body weight in mice with metabolic syndrome compared to control mice. These observations suggest the potential beneficial effect of limonite as a health supplement to prevent the development of diabetes mellitus.

The explanation for the beneficial effects of limonite is unclear. The high iron (ferric oxide) content of limonite suggests that iron might play a role. However, evidence from many studies has shown that iron overload or increased organ iron accumulation is linked to DM condition rather than DM inhibition. ${ }^{34}$ For example, glucose intolerance due to impaired insulin secretion is common in animal models of hemochromatosis and humans with thalassemia and hemochromatosis. ${ }^{34-37}$ In addition, none of our models of glucose intolerance had iron overload, as demonstrated by the liver CT study and by the normal levels of iron in plasma and liver tissue. Ferrous iron $\left(\mathrm{Fe}^{2+}\right)$ is the absorbable form of iron by the intestinal 
A Order

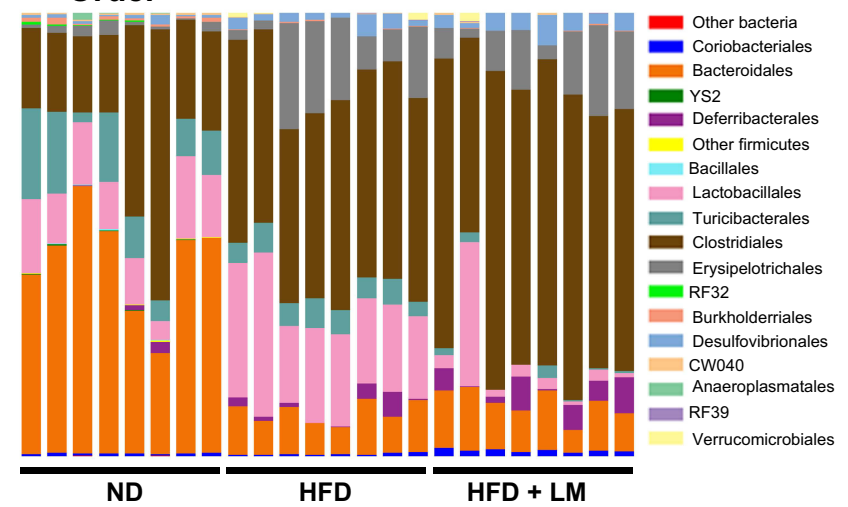

ND

HFD

HFD + LM
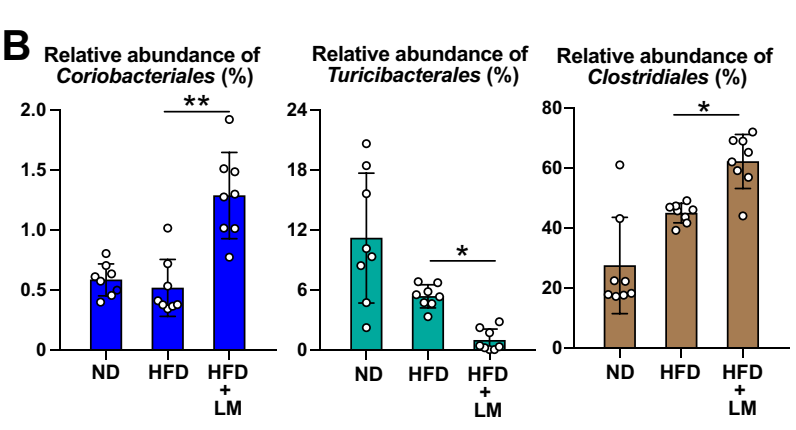

\section{Family}
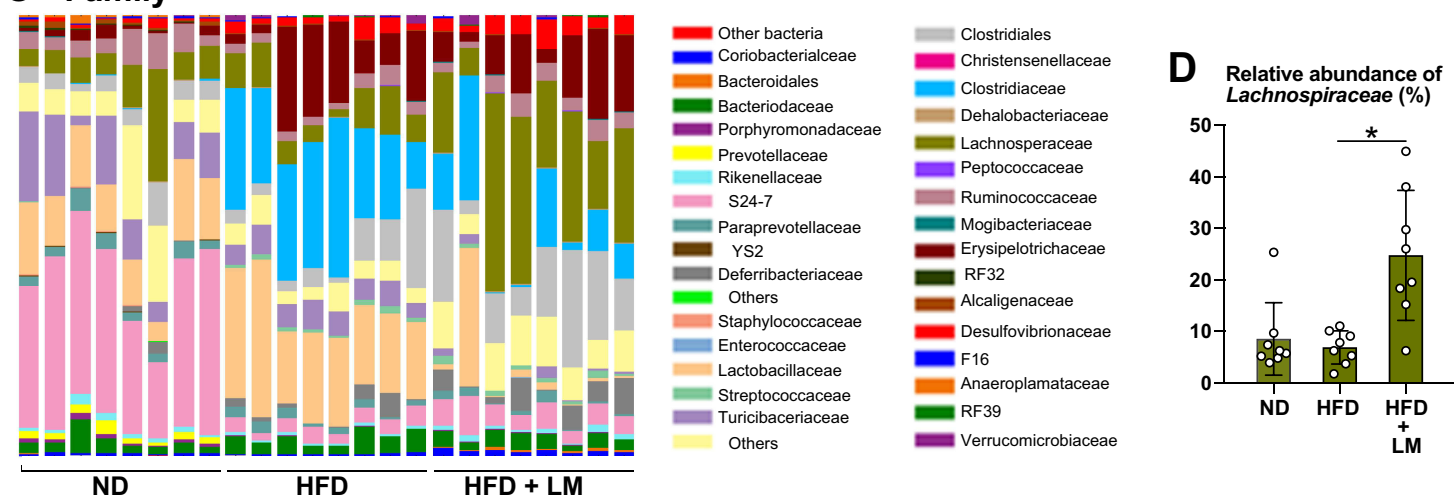

\section{E Genus}
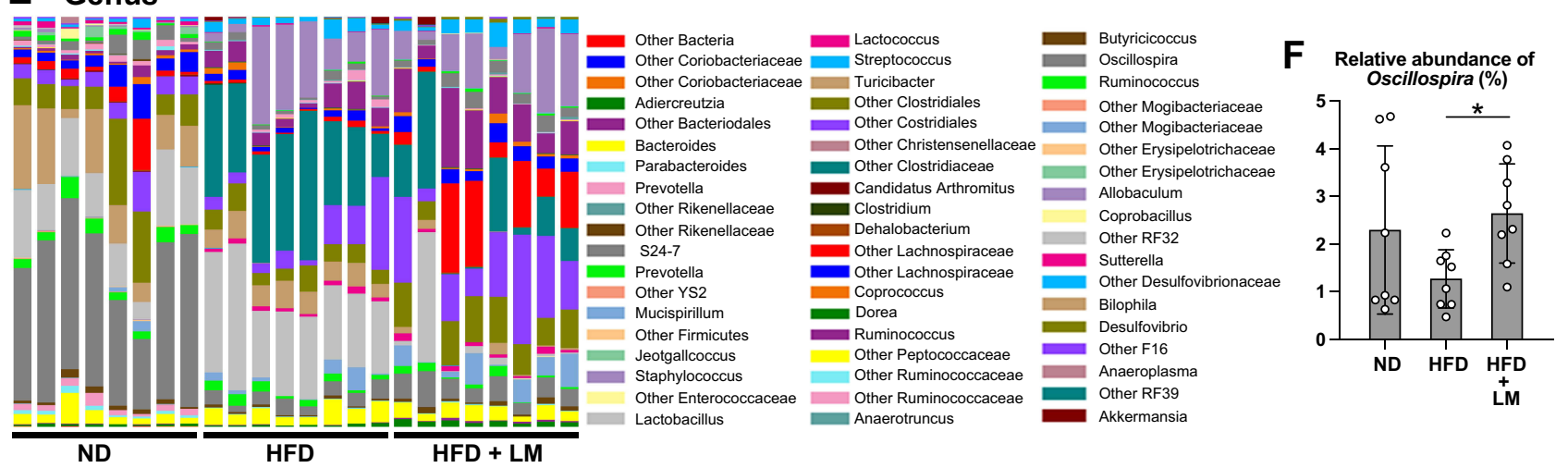

Figure 7 Remodeling of the gut microbiome in mice fed with an oral supplement of limonite. Mice received a high-fat diet (HFD, $n=8)$, a high-fat diet with limonite supplement (HFD+LM, $n=8)$, or a normal diet $(N D, n=8)$. Fecal samples were collected from each mouse, and DNA was extracted for sequencing the small subunit ribosomal RNA hypervariable regions as described under Materials and Methods. An evaluation was performed at order (A and B), family (C and $\mathbf{D})$, and genus (E and $\mathbf{F}$ ) levels. Data are the means \pm S.D. Statistical analysis was performed by Kruskal-Wallis ANOVA with Dunn's test. ${ }^{*} \mathrm{p}<0.05$; ${ }^{* *} \mathrm{p}<0.001$.

epithelial cells, and the limonite iron is in ferric oxide $\left(\mathrm{Fe}^{3}\right.$ ${ }^{+}$) form. ${ }^{38}$ Therefore, it is not surprising that mice taking oral limonite have no iron overload. Change in the plasma level GLP-1 also appears unrelated to the beneficial effects of adding limonite to the diet. GLP-1 is an incretin hormone that improves glucose tolerance by stimulating insulin secretion. ${ }^{39,40}$ It is produced and secreted by endocrine cells from the small intestine after nutrient ingestion. ${ }^{39}$ In the present study, mice under a high-fat diet and receiving an oral supplement of limonite showed significantly reduced plasma levels of GLP-1 compared to untreated mice, ruling out the involvement of GLP-1 in the beneficial effect of limonite supplement.

Silica is another abundant component of limonite that may exert beneficial effects in DM. Previous evidence has shown that administration of silica reduces the activity of 
macrophages, the expression of T-helper (h) 1 cytokine, and the autoimmune response of cytotoxic CD8+ T cells to pancreatic islet $\beta$-cells to block the development of type 1 DM in animal models of the disease. ${ }^{41-46}$ Consistent with these observations, in the present study, we found that limonite supplement significantly inhibits the expression of Th1 cytokines (IL-12) and inflammatory cytokines (IL6 , IL-8, TNF- $\alpha$ ) from intestinal epithelial cells in vitro and reduced the circulating levels of inflammatory chemokines (MCP-1) and cytokines (IL-6, TNF- $\alpha$ ) in a mouse model of insulin resistance. Therefore, the presence of silica may explain in part the protective activity of limonite supplement in DM.

Accumulating evidence suggests that dysbiosis of the gut microbiome caused by genetic alterations and environmental factors, including diet, may contribute to DM's pathogenesis and its commonly associated complications. ${ }^{47-50}$ The significant correlation of the bacterial communities with glucose metabolism and insulin resistance parameters observed in our present study also supports the results of these previous studies. Limonite can alter the composition of microbial communities. ${ }^{11,19}$ Therefore, we hypothesized that remodeling of the gut microbial community could explain in part the beneficial effects of limonite on impaired glucose tolerance. We found that the bacterial populations that are low in patients with gestational DM (Coriobacteriales, Lachnospiraceae) ${ }^{50}$ prediabetes (Clostridiales), ${ }^{51}$ or obesity (Oscillospira) ${ }^{52}$ were significantly increased in obese mice fed with limonite supplement compared to untreated mice. By contrast, Turicibacteriales frequently associated with insulin resistance and obesity were significantly decreased by limonite supplement in our obese mouse model compared to control mice. ${ }^{53,54}$ On the other hand, we found that abundant microbial communities (Proteobacteria, Prevotella) ${ }^{55-58}$ or protective (Bacteroidetes, Allobaculum) $)^{59,60}$ in type 1 DM increased in our DM mouse model fed with limonite supplement compared to untreated mice, and Tenericutes that are scarce in mice with obesity were increased in mice with DM receiving limonite. ${ }^{61,62}$ Overall, these observations suggest that limonite supplement ameliorates glucose intolerance, at least in part, by remodeling the gut microbial population.

\section{Limitation}

The use of a relatively small number of mice in each treatment group, failure to identify the active component of limonite that protects against glucose intolerance, and the use of a single dose of limonite are limitations of the present study.

\section{Conclusion}

In brief, this study demonstrates that limonite supplements ameliorate abnormal glucose metabolism in DM and obese conditions. Gut microbial remodeling, inhibition of inflammatory cytokines, and regulation of the host immune response may explain the limonite's beneficial properties. However, global assessment of safety and toxicity should be performed before its application in humans.

\section{Abbreviations}

DM, diabetes mellitus; ND, normal diet; LMD, limonite diet; STZ, streptozotocin; SAL, saline; HFD, high-fat diet; LM, limonite.

\section{Acknowledgment}

This research was supported in part by a grant from Tanisake Corporation and a grant from the Japan Society for the Promotion of Science (Kakenhi-Grant No 20K08564). The funders had no role in study design, data analysis, decision to publish, or manuscript preparation.

\section{Disclosure}

Hiroyuki Mukaiyama, Norio Takagi, Katsumi Shimizu are employees of Tanisake Corporation, which is the company that funded in part the present study. Takehiro Takagi is a relative of one of the employees of Tanisake Corporation. Hiroyuki Mukaiyama, Esteban C Gabazza, Nario Takagi, and Katsumi Shimizu have a patent JP2020-075683 pending to Tanisake co., Ltd. Esteban C Gabazza was the recipient of a grant from Tanisake Corporation to support the present investigation. Esteban C Gabazza received a grant from the Japan Society for the Promotion of Science to support this study in part. Taro Yasuma reports grants from the Japan Society for the Promotion of Science, outside the submitted work. The other authors declared no conflicts of interest regarding data reported in this work.

\section{References}

1. Chen L, Magliano DJ, Zimmet PZ. The worldwide epidemiology of type 2 diabetes mellitus--present and future perspectives. Nat Rev Endocrinol. 2011;8(4):228-236. doi:10.1038/nrendo.2011.183

2. Murray CJ, Vos T, Lozano R, et al. Disability-adjusted life years (DALYs) for 291 diseases and injuries in 21 regions, 1990-2010: a systematic analysis for the Global Burden of Disease Study 2010. Lancet. ～2012;380(9859):2197-2223. doi:10.1016/S0140-6736(12) 61689-4 
3. Atun R, Davies JI, Gale EAM, et al. Diabetes in sub-Saharan Africa: from clinical care to health policy. Lancet Diabetes Endocrinol. 2017;5(8):622-667. doi:10.1016/S2213-8587(17)30181-X

4. Bommer C, Heesemann E, Sagalova V, et al. The global economic burden of diabetes in adults aged 20-79 years: a cost-of-illness study. Lancet Diabetes Endocrinol. 2017;5(6):423-430. doi:10.1016/S22138587(17)30097-9

5. Gregg EW, Menke A Diabetes and disability. In: Cowie CC, Casagrande SS, et al, editors. Diabetes in America, 3rd edition. Bethesda (MD): National Institute of Diabetes and Digestive and Kidney Diseases (US); 2018. Available from: https://www.ncbi.nlm. nih.gov/books/NBK567985. Accessed July 02, 2021. /

6. Amos AF, McCarty DJ, Zimmet P. The rising global burden of diabetes and its complications: estimates and projections to the year 2010. Diabet Med. 1997;14(Suppl 5):S1-S85.

7. Ghosh-Swaby OR, Goodman SG, Leiter LA, et al. Glucose-lowering drugs or strategies, atherosclerotic cardiovascular events, and heart failure in people with or at risk of type 2 diabetes: an updated systematic review and meta-analysis of randomised cardiovascular outcome trials. Lancet Diabetes Endocrinol. 2020;8(5):418-435. doi:10.1016/S2213-8587(20)30038-3

8. Organization WH. Global Action Plan for the Prevention and Control of Noncommunicable Diseases: 2013-2020. World Health Organization. Available from: http://www.who.int/nmh/events/ncd action_plan/en/. Accessed June 17, 2017.

9. Bommer C, Sagalova V, Heesemann E, et al. Global economic burden of diabetes in adults: projections from 2015 to 2030. Diabetes Care. 2018;41(5):963-970. doi:10.2337/dc17-1962

10. International Diabetes F. IDF diabetes atlas. International diabetes, federation. Available from: http://www.diabetesatlas.org. Accessed March 9, 2015.

11. Mustapha NA, Toya S, Maeda T. Effect of aso limonite on anaerobic digestion of waste sewage sludge. AMB Express. 2020;10(1):74. doi:10.1186/s13568-020-01010-w

12. Dermenci KB, Buluc AF, Turan S. The effect of limonite addition on the performance of Li7La3Zr2O12. Ceram Int. 2019;45 (17):21401-21408. doi:10.1016/j.ceramint.2019.07.128

13. Esen Y, Dogan ZM. Investigation of usability of limonite aggregate in heavy-weight concrete production. Prog Nucl Energy. 2018;105:185-193. doi:10.1016/j.pnucene.2018.01.011

14. Kaneko T, Sugita S, Tamura M, Shimasaki K, Makino E, Silalahi LH. Highly active limonite catalysts for direct coal liquefaction. Fuel. 2002;81(11-12):1541-1549. doi:10.1016/S0016-2361(02)00079-0

15. Yan XL, Shao JQ, Wen QQ, Shen JF. Stabilization of soil arsenic by natural limonite after mechanical activation and the associated mechanisms. Sci Total Environ. 2020;708:135118. doi:10.1016/j. scitotenv.2019.135118

16. Mochizuki Y, Ogawa A, Tsubouchi N. Removal of hydrogen sulfide and ammonia by goethite-rich limonite in the coexistence of coke oven gas components. ISIJ Int. 2017;57(3):435-442. doi:10.2355/ isijinternational.ISIJINT-2016-561

17. Toda K, Tanaka T, Tsuda Y, et al. Sulfurized limonite as material for fast decomposition of organic compounds by heterogeneous fenton reaction. $J$ Hazard Mater. 2014;278:426-432. doi:10.1016/j. jhazmat.2014.06.033

18. Zhou Q, Jiang X, Li X, Jiang W. The control of H2S in biogas using iron ores as in situ desulfurizers during anaerobic digestion process. Appl Microbiol Biotechnol. 2016;100(18):8179-8189. doi:10.1007/ s00253-016-7612-7

19. Xu LF, Peng SC, Dong DS, et al. Performance and microbial community analysis of dry anaerobic co-digestion of rice straw and cow manure with added limonite. Biomass Bioenergy. 2019;126:41-46. doi:10.1016/j.biombioe.2019.04.026

20. Imshenetsky AA, Abyzov SS, Voronov GT, et al. Exobiology and the effect of physical factors on micro-organisms. Life Sci Space Res. 1967;5:250-260.
21. Yang G, Wei J, Liu P, et al. Role of the gut microbiota in type 2 diabetes and related diseases. Metabolism. 2021;117:154712. doi:10.1016/j.metabol.2021.154712

22. Yasuma T, Yano Y, D'Alessandro-Gabazza CN, et al. Amelioration of diabetes by protein S. Diabetes. 2016;65(7):1940-1951. doi:10.2337/ db15-1404

23. Nahdi A, John A, Raza H. Elucidation of molecular mechanisms of streptozotocin-induced oxidative stress, apoptosis, and mitochondrial dysfunction in Rin-5F pancreatic beta-cells. Oxid Med Cell Longev. 2017;7054272. doi:10.1155/2017/7054272

24. Nishihama K, Yasuma T, Yano Y, et al. Anti-apoptotic activity of human matrix metalloproteinase-2 attenuates diabetes mellitus. Metabolism. 2018;82:88-99. doi:10.1016/j.metabol.2018.01.016

25. Chelakkot-Govindalayathil AL, Mifuji-Moroka R, D'AlessandroGabazza $\mathrm{CN}$, et al. Protein S exacerbates alcoholic hepatitis by stimulating liver natural killer T cells. J Thromb Haemost. 2015;13 (1):142-154. doi:10.1111/jth.12789

26. Haffner SM, Miettinen H, Stern MP. The homeostasis model in the San Antonio Heart Study. Diabetes Care. 1997;20(7):1087-1092. doi:10.2337/diacare.20.7.1087

27. Katsuki A, Sumida Y, Urakawa H, et al. Neither homeostasis model assessment nor quantitative insulin sensitivity check index can predict insulin resistance in elderly patients with poorly controlled type 2 diabetes mellitus. J Clin Endocrinol Metab. 2002;87(11):5332-5335. doi:10.1210/jc.2002-020486

28. D’Alessandro-Gabazza CN, Kobayashi T, Yasuma T, et al. A Staphylococcus pro-apoptotic peptide induces acute exacerbation of pulmonary fibrosis. Nat Commun. 2020;11(1):1539. doi:10.1038/ s41467-020-15344-3

29. Takagi T, Naito Y, Inoue R, et al. The influence of long-term use of proton pump inhibitors on the gut microbiota: an age-sex-matched case-control study. J Clin Biochem Nutr. 2018;62(1):100-105. doi: $10.3164 /$ jcbn. $17-78$

30. Li W, Fu L, Niu B, Wu S, Wooley J. Ultrafast clustering algorithms for metagenomic sequence analysis. Brief Bioinform. 2012;13 (6):656-668. doi:10.1093/bib/bbs035

31. Caporaso JG, Kuczynski J, Stombaugh J, et al. QIIME allows analysis of high-throughput community sequencing data. Nat Methods. 2010;7(5):335-336. doi:10.1038/nmeth.f.303

32. DeSantis TZ, Hugenholtz P, Larsen N, et al. Greengenes, a chimera-checked 16S rRNA gene database and workbench compatible with ARB. Appl Environ Microbiol. 2006;72(7):5069-5072. doi:10.1128/AEM.03006-05

33. Wang Q, Garrity GM, Tiedje JM, Cole JR. Naive bayesian classifier for rapid assignment of rRNA sequences into the new bacterial taxonomy. Appl Environ Microbiol. 2007;73(16):5261-5267. doi:10.1128/AEM.00062-07

34. Moore WT, Bowser SM, Fausnacht DW, Staley LL, Suh KS, Liu D. Beta cell function and the nutritional state: dietary factors that influence insulin secretion. Curr Diab Rep. 2015;15(10):76. doi:10.1007/ s11892-015-0650-1

35. Dmochowski K, Finegood DT, Francombe W, Tyler B, Zinman B. Factors determining glucose tolerance in patients with thalassemia major. J Clin Endocrinol Metab. 1993;77(2):478-483. doi:10.1210/ jcem.77.2.8345055

36. Merkel PA, Simonson DC, Amiel SA, et al. Insulin resistance and hyperinsulinemia in patients with thalassemia major treated by hypertransfusion. $N$ Engl $J$ Med. 1988;318(13):809-814. doi:10.1056/NEJM198803313181303

37. Moirand R, Adams PC, Bicheler V, Brissot P, Deugnier Y. Clinical features of genetic hemochromatosis in women compared with men. Ann Intern Med. 1997;127(2):105-110. doi:10.7326/0003-4819-1272-199707150-00002

38. Gulec S, Anderson GJ, Collins JF. Mechanistic and regulatory aspects of intestinal iron absorption. Am J Physiol Gastrointest Liver Physiol. 2014;307(4):G397-G409. doi:10.1152/ajpgi.00348.2013 
39. Holst JJ. The incretin system in healthy humans: the role of GIP and GLP-1. Metabolism. 2019;96:46-55. doi:10.1016/j.metabol. 2019.04.014

40. Lee YS, Jun HS. Anti-diabetic actions of glucagon-like peptide-1 on pancreatic beta-cells. Metabolism. 2014;63(1):9-19. doi:10.1016/j. metabol.2013.09.010

41. Jun HS, Yoon CS, Zbytnuik L, van Rooijen N, Yoon JW. The role of macrophages in $\mathrm{T}$ cell-mediated autoimmune diabetes in nonobese diabetic mice. J Exp Med. 1999;189(2):347-358. doi:10.1084/ jem.189.2.347

42. Kolb H, Burkart V, Appels B, et al. Essential contribution of macrophages to islet cell destruction in vivo and in vitro. $J$ Autoimmun. 1990;3(Suppl 1):117-120. doi:10.1016/s0896-8411(09)90020-8

43. Lee KU, Amano K, Yoon JW. Evidence for initial involvement of macrophage in development of insulitis in NOD mice. Diabetes. 1988;37(7):989-991. doi:10.2337/diab.37.7.989

44. Lee KU, Pak CY, Amano K, Yoon JW. Prevention of lymphocytic thyroiditis and insulitis in diabetes-prone BB rats by the depletion of macrophages. Diabetologia. 1988;31(6):400-402. doi:10.1007/ BF02341511

45. Oschilewski U, Kiesel U, Kolb H. Administration of silica prevents diabetes in BB-rats. Diabetes. 1985;34(2):197-199. doi:10.2337/ diab.34.2.197

46. Scott FW, Rowsell P, Wang GS, Burghardt K, Kolb H, Flohe S. Oral exposure to diabetes-promoting food or immunomodulators in neonates alters gut cytokines and diabetes. Diabetes. 2002;51(1):73-78. doi:10.2337/diabetes.51.1.73

47. Ding S, Chi MM, Scull BP, et al. High-fat diet: bacteria interactions promote intestinal inflammation which precedes and correlates with obesity and insulin resistance in mouse. PLoS One. 2010;5(8): e12191. doi:10.1371/journal.pone.0012191

48. Massey W, Brown JM. The gut microbial endocrine organ in type 2 diabetes. Endocrinology. 2021;162(2). doi:10.1210/endocr/bqaa235

49. Zhang S, Cai Y, Meng C, et al. The role of the microbiome in diabetes mellitus. Diabetes Res Clin Pract. 2021;172:108645. doi:10.1016/j.diabres.2020.108645

50. Zhang Y, Chen T, Zhang Y, et al. Contribution of trace element exposure to gestational diabetes mellitus through disturbing the gut microbiome. Environ Int. 2021;153:106520. doi:10.1016/j. envint.2021.106520

51. Allin KH, Tremaroli V, Caesar R, et al. Aberrant intestinal microbiota in individuals with prediabetes. Diabetologia. 2018;61(4):810-820. doi:10.1007/s00125-018-4550-1
52. Kashtanova DA, Tkacheva ON, Doudinskaya EN, et al. Gut microbiota in patients with different metabolic statuses: Moscow Study. Microorganisms. 2018;6(4):98. doi:10.3390/microorganisms6040098

53. Lai KP, Ng AH-M, Wan HT, et al. Dietary exposure to the environmental chemical, PFOS on the diversity of gut microbiota, associated with the development of metabolic syndrome. Front Microbiol. 2018;9:2552. doi:10.3389/fmicb.2018.02552

54. Yuan X, Chen R, Zhang Y, Lin X, Yang X, McCormick KL. Gut microbiota of Chinese obese children and adolescents with and without insulin resistance. Front Endocrinol. 2021;12:636272. doi:10.3389/fendo.2021.636272

55. Gavin PG, Mullaney JA, Loo D, et al. Intestinal metaproteomics reveals host-microbiota interactions in subjects at risk for type 1 diabetes. Diabetes Care. 2018;41(10):2178-2186. doi:10.2337/dc180777

56. Higuchi BS, Rodrigues N, Gonzaga MI, et al. Intestinal dysbiosis in autoimmune diabetes is correlated with poor glycemic control and increased interleukin-6: a Pilot Study. Front Immunol. 2018;9:1689. doi:10.3389/fimmu.2018.01689

57. Jamshidi $\mathrm{P}$, Hasanzadeh S, Tahvildari A, et al. Is there any association between gut microbiota and type 1 diabetes? A systematic review. Gut Pathog. 2019;11(1):49. doi:10.1186/s13099-019-0332-7

58. Vatanen T, Franzosa EA, Schwager R, et al. The human gut microbiome in early-onset type 1 diabetes from the TEDDY study. Nature. 2018;562(7728):589-594. doi:10.1038/s41586-018-0620-2

59. Krych Ł, Nielsen DS, Hansen AK, Hansen CH. Gut microbial markers are associated with diabetes onset, regulatory imbalance, and IFN- $\gamma$ level in NOD Mice. Gut Microbes. 2015;6(2):101-109. doi:10.1080/19490976.2015.1011876

60. Ma Q, Li Y, Wang J, et al. Investigation of gut microbiome changes in type 1 diabetic mellitus rats based on high-throughput sequencing. Biomed Pharmacother. 2020;124:109873. doi:10.1016/j. biopha.2020.109873

61. Benedict C, Vogel H, Jonas W, et al. Gut microbiota and glucometabolic alterations in response to recurrent partial sleep deprivation in normal-weight young individuals. Mol Metab. 2016;5 (12):1175-1186. doi:10.1016/j.molmet.2016.10.003

62. Everard A, Lazarevic V, Gaia N, et al. Microbiome of prebiotic-treated mice reveals novel targets involved in host response during obesity. ISME J. 2014;8(10):2116-2130. doi:10.1038/ ismej.2014.45
Journal of Inflammation Research

\section{Publish your work in this journal}

The Journal of Inflammation Research is an international, peerreviewed open-access journal that welcomes laboratory and clinica findings on the molecular basis, cell biology and pharmacology of inflammation including original research, reviews, symposium reports, hypothesis formation and commentaries on: acute/chronic inflammation; mediators of inflammation; cellular processes; molecular mechanisms; pharmacology and novel anti-inflammatory drugs; clinical conditions involving inflammation. The manuscript management system is completely online and includes a very quick and fair peerreview system. Visit http://www.dovepress.com/testimonials.php to read real quotes from published authors. 